\title{
Temas, personajes e ideas en la primera década de teatro benaventino: evolución e intertextualidades
}

\author{
Diana Muela Bermejo \\ Universidad San Jorge
}

Título: Temas, personajes e ideas en la primera década de teatro benaventino: evolución e intertextualidades.

Resumen: La renovación teatral de Jacinto Benavente sentó una de las bases de la escritura dramática contemporánea, que luego fue continuada por otros escritores del siglo XX español. La comedia burguesa por la que es recordado en la actualidad fue, no obstante, fruto de una compleja evolución que parte de un tanteo de temas e ideas que no han sido apenas estudiados. En este artículo se analizan los personajes, argumentos e intertextualidades que se observan en las obras estrenadas por el dramaturgo madrileńo en su primera década: desde 1894 hasta 1905.

Palabras clave: Jacinto Benavente, Modernismo español, Edad de Plata, Comedia Burguesa, Drama.

Fecha de recepción: 4/9/2016.

Fecha de aceptación: 11/10/2016.
Title: Themes, Characters and Ideas in the First Decade of the Benavente's Theatre: Evolution and Intertextualities.

Abstract: Jacinto Benavente's theatrical innovation established one of the bases of dramatic writing that was afterwards continued by other authors of the Spanish twentieth century. Nevertheless, his nowadays well-known middle-class comedy was the outcome of a complex evolution that began with an exploration of affairs and ideas which practically have not been studied yet. In this work the characters, arguments and intertextualities of the pieceworks that were presented during Jacinto Benavente's first decade (from 1894 to 1905 ) are analysed.

Key words: Jacinto Benavente, Spanish Modernism, Silver Age, Middle-class Comedy, Drama.

Date of Receipt: 4/9/2016.

Date of Approval: 11/10/2016.

Los años que abarcan desde el primer estreno de Jacinto Benavente en 1894 hasta el final de la temporada de 1904-1905 se rigen por unas líneas temáticas recurrentes que comprenden géneros diversos (comedias, dramas y obras breves de distinta denominación). Se observa, no obstante, 
una evolución en el tratamiento de estos asuntos, desde sátiras aristocráticas hasta los primeros dramas de ideas y las obras fundamentadas en la escenografía. El objetivo de este artículo reside, principalmente, en mostrar cómo fue configurándose la dramaturgia de Benavente desde sus inicios, atendiendo a los temas y tipos de personajes que ocuparon su atención en los momentos en los que el teatro español experimentaba una renovación que se había fraguado en la década anterior. Por lo tanto, es necesario mantener el orden cronológico en el análisis, pues deben ser tenidos en cuenta los cambios que se produjeron en las circunstancias teatrales que rodearon sus estrenos, quizá eclipsados hasta el momento por otros focos de análisis, no menos importantes, pero dependientes de su contexto. No se pretende, pues, ofrecer al lector un nuevo estudio semiótico de los dramas, sino mostrar en qué medida éstos fueron condicionados por los factores externos (tipología de los teatros, gustos del público, elecciones en las compañías, etc.) y otros aspectos de la sociabilidad teatral y de la formación de Benavente como escritor y crítico; a la luz de la nueva documentación que hoy se posee.

Así pues, el análisis temático se complementará, por un lado, con una metodología historiográfica y sociológica que permita definir el perfil dramatúrgico benaventino $y$, por otro, con una perspectiva intertextual que ilumine recurrencias frecuentes, analogías y otros aspectos comunes a obras de distintos géneros (comedias, dramas y teatro breve).

El trabajo se divide en ocho apartados que corresponden a una clasificación por etapas de la obra del primer Benavente. El terminus ad quem se ha establecido en la temporada de $1904-1905$ por ser, desde mi punto de vista, el momento de consagración oficial de Jacinto Benavente como uno de los grandes dramaturgos nacionales de la época, pues en el estreno de Rosas de otoño, por primera vez, los espectadores lo aplaudieron de manera unánime. A partir de entonces, Benavente comenzó otra etapa, condicionada por un público ya fiel, que deberá ser estudiada con detalle atendiendo no sólo a sus obras canónicas, sino al conjunto de su producción literaria. El corpus comprende, pues, todas las obras estrenadas por Benavente desde El nido ajeno (Teatro de la Comedia, 6 de octubre 1894) hasta Rosas de otoño (Teatro Español, 13 de abril de 1905), sin incluir traducciones ni espectáculos musicales. El teatro breve se analiza en un apartado final, pues ha recibido mayor atención crítica y su carac- 
terización atiende a aspectos estructurales cuyo análisis debe abordarse de manera independiente.

Se partirá de un estudio de las primeras obras, que guardan una estrecha relación entre sí y que corresponden a una temática general relacionada con la sátira y la lucha de clases desde un punto de vista humorístico al que seguirá, en el siguiente apartado, el corpus de obras centradas en los conflictos amorosos, más sutiles en la crítica que las anteriores. A ellos acompañará una tercera sección dedicada a las obras ambientadas en provincias, que albergan ciertas particularidades, como se verá más adelante, que las distinguen de las anteriores (crítica política, personajestipo recurrentes - y su dependencia de los actores que los encarnaron-, etc.). Los estrenos del Lara han sido analizados de forma independiente, pues las particularidades cómicas de la sala condicionaron el tipo de creación (en su brevedad y en su contenido paródico), así como su fundamentación en personajes característicos alejados de las primeras actrices (en menor medida, de los actores) de otras compañías. El estudio finalizará con un acercamiento a los dramas de ideas como germen del teatro posterior y a la problemática surgida con el teatro escenográfico que parte del estreno el 17 de marzo de 1903 de La noche del sábado y de su entrada en el Teatro Español, que entonces dirigía el matrimonio Guerrero-Mendoza.

Por último, se ha prestado especial atención a las notas y argumentos metateatrales que aparecen en sus obras y que ayudan a perfilar la poética dramática benaventina, así como a las intertextualidades de personajes, temas e ideas presentes en las comedias, dramas y algunas escenas breves publicadas en la prensa.

Desde el punto de vista bibliográfico tradicional, el teatro benaventino ha sido clasificado en dos grandes etapas, anterior y posterior al inicio de la Primera Guerra Mundial. En la primera etapa, que cuenta con un mayor número de estudios que la segunda - terreno prácticamente yermo- se han analizado las comedias satíricas, por una parte, con especial atención a las de los primeros años y, por otra, los dramas sentimentales a partir de 1901 .

Starkie propuso una clasificación temático-cronológica en torno a los dos bloques citados, en la que se distinguían obras realistas y de fantasía (anteriores a 1914) y, con una denominación común, obras a partir de 
1914. En el primer grupo, las obras realistas comprendían sátiras cosmopolitas y rurales, obras de la vida de la clase media y obras dialécticas; y en el segundo, las fantasías abarcaban estudios psicológicos, comedias románticas y de pompa y boato y también grotescas ${ }^{1}$. Ortiz siguió el mismo esquema general de Starkie pero fijó la frontera de 1901 como eje delimitador de dos tipos de teatro benaventino: el primero (1894-1901) definido por su originalidad y sentido de la realidad opuesto al gusto del público y por su sátira ${ }^{2}$; , el segundo, marcado por el triunfo de su dramaturgia y por la ampliación de sus horizontes y de su repertorio ${ }^{3}$.

Sheehan interpretó los primeros años del teatro de Benavente desde el punto de vista del concepto de "Generación del 98" y analizó las obras según su acercamiento o distanciamiento a la ideología de los autores enmarcados bajo esta denominación, y aceptó el límite de 1914 como final de una etapa generacional, no sólo benaventina ${ }^{4}$.

No obstante, la clasificación de Starkie parece la más acertada desde el punto de vista del contenido de las obras, pero deben ser tenidos en cuenta otros factores que, a la luz de los textos benaventinos que hoy se conocen, facultan para nuevos parámetros de análisis; a saber: el condicionamiento de los espacios teatrales, la evolución de la opinión del público y de la crítica y las escenas publicadas en la prensa como base de la primera década de creación teatral de Jacinto Benavente. A este respecto, deben atenderse los estudios de Rubio Jiménez ${ }^{5}$ y Yagüe Ferrer ${ }^{6}$; el primero, por sentar las bases de un análisis histórico y sociológico de las particularidades teatrales de la última década del siglo XIX; y el segundo, por recopilar una bibliografía exhaustiva de artículos periodísticos benaventinos (además de ediciones, traducciones, etc.) que he podido completar

1 Walter Starkie, Jacinto Benavente, Oxford, Oxford University Press, 1924, pp. 43172.

2 Julia Ortiz Griffin, Drama y sociedad en la obra de Benavente (1894-1914), Nueva York, Anaya-Las Américas, 1974, p. 138.

3 Ibidem, p. 169.

4 Robert Louis Sheehan, Benavente and the Spanish Panorama. 1894-1954, Chapel Hill, N. C., Estudios de Hispanófila, 1976.

5 Jesús Rubio Jiménez, Ideología y teatro en España (1890-1900), Zaragoza, Universidad de Zaragoza-Libros Pórtico, 1982.

6 María Isabel Yagüe Ferrer, Bibliografía general de Jacinto Benavente, Zaragoza, Prensas de la Universidad de Zaragoza, 2014. 
con más de ciento cuarenta referencias nuevas, inéditas hasta ahora. Cabe destacar, además, los análisis de Simón Palmer ${ }^{7}$, Romero Tobar ${ }^{8}$ y Thion ${ }^{9}$, entre otros, que ofrecen datos sustanciales para la contextualización histórica necesaria de este estudio y, especialmente, los trabajos presentados en el congreso Jacinto Benavente en el teatro español, celebrado en Murcia en $2005^{10}$, pues, en su conjunto, son los más actualizados sobre crítica benaventina.

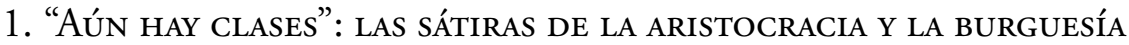 PARVENUE}

En un artículo publicado en su sección “De sobremesa” (1907), Benavente explicó las razones que le llevaron a escoger la sátira de la aristocracia como uno de los asuntos más representativos de su teatro:

Si algunas veces he fustigado (según cliché) a nuestra aristocracia, no fue por prevención desfavorable contra ella, sino que puesto a satirizar y dada la natural y pícara preferencia del público por reír a costa de alguien, me pareció más piadoso hacer reír a costa de los que gozan de muchas ventajas en la vida, que a costa de los humildes que trabajan y padecen escasez de todo. Nunca me ha parecido que el tener hambre sea cosa de risa, y ya sabemos que en la mitad de nuestro teatro cómico el hambriento es principal motivo de regocijo ${ }^{11}$.

7 María del Carmen Simón Palmer, "Construcción y apertura de teatros madrileños en el siglo XIX”, Segismundo: Revista Hispánica de Teatro, 11 (1975), pp. 85-137.

8 Leonardo Romero Tobar, "Relato, teatro, novela dialogada en el Fin de Siglo", en Estudios de literatura comparada: norte y sur, la sátira, transferencia y recepción de géneros y formas textuales, ed. José Enrique Martínez Fernández, León, Universidad de León. Servicio de Publicaciones, 2002, pp. 717-730.

9 Dolores Thion Soriano, "Teatro y opinión pública en la prensa de entresiglos", en Théatre, public, société. Actes du III Colloque International sur le théâtre hispanique, hispano-américain et mexicain en France, 10-12 de octubre de 1996, Perpignan, Presses Universitaires de Perpignan, 1998, pp. 55-70.

10 Jacinto Benavente en el teatro español, eds. Mariano de Paco y Francisco Javier Díez de Revenga, Murcia, Fundación Cajamurcia, 2005.

11 Jacinto Benavente, "De sobremesa”, El Imparcial, XLI, 14434 (27/V/1907), p. 3. 
No obstante, Lázaro recogió unas palabras del dramaturgo madrileño (aunque no citó su fuente) donde explicaba la elección de la sátira de las clases altas en términos de imitación francesa:

Cuando yo empecé a escribir se me tachaba de extranjerismo, y es cierto que había en mis obras esta tendencia. Entonces se creía que todo lo español era malo, y los que empezábamos a escribir no oíamos hablar más que de los defectos de nuestro país y de las excelencias de todo lo extranjero. [...] Se nos mostraba, por ejemplo, la ingenuidad y la gracia refinadas que había en el teatro francés, y yo en mis primeras obras quise demostrar que en castellano también se podían decir gracias e ingeniosidades. Además, la alta sociedad que pintaba yo en aquellas comedias es lo mismo en todas partes. De ahí el que aquellas comedias se parezcan a las de otros países, dada la identidad del modelo ${ }^{12}$.

Ambas explicaciones se muestran coherentes con las ideas benaventinas expresadas en sus artículos de prensa y definen las líneas de su primera creación dramática, fundamentada en la sátira de las clases adineradas de estilo francés y, en menor medida, en la parodia del habla de provincias, siempre a través de personajes que viven cómodamente de su trabajo.

La alta burguesía y la aristocracia espańolas son objeto de las burlas benaventinas desde dos perspectivas: económica y moral, ambas muy presentes en el teatro francés finisecular. El primer caso, que afecta a la decadencia de los títulos nobiliarios y a la ruina de las familias españolas más antiguas, ocupa un lugar protagónico en Gente conocida - Teatro de la Comedia, 21 de octubre de 1896 - y La comida de las fieras - Teatro de la Comedia, 7 de noviembre de 1898-, donde se constituye como eje central y adopta una visión mordaz y fustigadora mayor a la de otras comedias. El segundo caso, donde se pone de manifiesto la falsa moral de apariencias y la frivolidad de este sector social, está presente en buena parte de sus escenas publicadas en la prensa y en obras representadas más ligeras, donde el asunto amoroso se erige como eje conductor de la trama: Lo cursi - Teatro de la Comedia, 19 de enero de 1901—, Amor de amar

12 Ángel Lázaro, Biografía de Jacinto Benavente, Madrid, Compañía Ibero-Americana de Publicaciones, 1930, p. 27. 
- Teatro de la Comedia, 24 de febrero de 1902-, El hombrecito - Teatro de la Comedia, 23 de marzo de 1903-, parte de Rosas de otoño y, con carácter más severo, en La gata de Angora - Teatro de la Comedia, 31 de marzo de 1900-.

Así pues, desde la perspectiva económica, Benavente parodió, no sólo como asunto central sino también en escenas secundarias, los conflictos entre aristocracia y burguesía originados por la decadencia de la primera y el ascenso social de la segunda. En Gente conocida arranca el conflicto de intereses ${ }^{13}$, pero se plantea con mayor complejidad en La comida de las fieras y en su antecedente "Escenas íntimas".

En la primera escena del acto II de esta comedia se produce una discusión entre Manolo, Marqués de Castrojeriz y Fermín Antón (en las "Escenas íntimas" el aristócrata era el Duque de Cerinola) en la que se ponen de manifiesto las tensiones entre ambas clases, pero desde una perspectiva amistosa. Por una parte, Castrojeriz se burla de Antón por su incultura, característica de la burguesía de negocios que carece de una educación cuidada y, por otra parte, Antón se reafirma en el poder que le otorga la riqueza. El raisonneur irónico de la obra, Tomillares, cierra el conflicto de la escena con una anécdota que transmite el sentimiento aristócrata de "aún hay clases", al que se aferran por la pérdida de bienes:

Eso me recuerda a una anécdota del príncipe de Gales. El célebre sastre Pool que vestía al príncipe, rabiaba por asistir a un baile de palacio. El príncipe, bondadoso como siempre, le invitó por fin a uno de ellos, y cuando la fiesta se hallaba en todo su apogeo, se acercó carińosamente al príncipe de la tijera y le preguntó: “¿Qué te parece el baile?..." "iPchs!... No está mal; pero hay gente de todas clases...". "Pero, querido Pool —repuso el príncipe—, ¿querías que todos fueran sastres?..." 14 .

13 Para un estudio detallado de Gente conocida, remito a mi libro Hacia la renovación del teatro en los albores del siglo XX: "Gente conocida", "La noche del sábado" y "Rosas de otoño", de Jacinto Benavente, Vigo, Academia del Hispanismo, 2017, en prensa; no trataré aquí con profundidad, por lo tanto, estas tres obras. En él se puede encontrar, asimismo, un análisis de la recepción (público, crítica, literatos, etc.) del primer teatro benaventino.

14 Jacinto Benavente, La comida de las fieras, en Obras completas, I, pp. 319-320. 
La alta burguesía, representada por Fermín Antón, ve a los aristócratas como holgazanes y aprovechados, las "fieras" que no se preocupan más que de su propia diversión, lo que corrobora Tomillares con su frase final del acto I:

Don Fermín: ¡Toda la pillería junta!

TEÓFILO: ¿Qué dice ese burgués?

Tomillares: No hagan ustedes caso.

[...]

Victoria (Desde la puerta de la serre): ... Hacen ustedes esperar a mis invitadas.

Don Fermín (A Tomillares): La comida de las fieras..., como usted dice.

Tomillares: Y que, no sé por qué, me parece que el domador ha llevado alguna dentellada. ¡Usted ha puesto ya un pie en esta casa!

Don Fermín: ¡Usted es el diablo! ¡Todo lo sabe!

Tomillares: ¡Práctica! Pues nada, don Fermín; cuando usted sea dueño de la casa, no nos suprima usted las comidas ${ }^{15}$.

En el acto III se escenifica el comportamiento de las fieras, que continúa con las palabras de los protagonistas en el cuadro final. El conflicto entre aristocracia (o, como en el caso de Victoria e Hipólito, burguesía arruinada) y burguesía adinerada se percibe desde una perspectiva irónica y ligera a través de las discusiones entre los nobles y Fermín Antón y, al mismo tiempo, con la óptica descarnada de la mezquindad de los miembros de una sociedad interesada y ruin: las fieras. Un ejemplo similar se halla en El hombrecito, donde el Marqués de Castrojeriz, padre de la protagonista de la comedia, se lamenta de la decadencia de la fortuna familiar, pues no obtiene beneficios de fincas ${ }^{16}$ (como la Duquesa de Garellano en Gente conocida).

En La gata de Angora la distancia entre las clases sociales no se muestra a través de la decadencia de la aristocracia, sino de la endogamia de las clases adineradas, que impiden a los artistas acceder a ellas por medio de las relaciones amorosas.

15 Ibidem, p. 329.

16 Jacinto Benavente, El hombrecito, en Obras completas, I, p. 36. 
La visión negativa de estas clases la encarna el personaje de Silvia y su representación como una gata de Angora, pues para Aurelio la elegancia simboliza la blancura de las almas pervertidas y de la sociedad, que al mismo tiempo atrae y asusta ${ }^{17}$. Por ello Pepe lo tilda de "artista domesticado" y parodia que haya sucumbido a la sociedad aristocrática de frivolidades y menudencias (el arte rico frente al arte pobre) ${ }^{18}$.

A diferencia de Gente conocida o de La comida de las fieras, donde la sátira de las clases altas adopta una perspectiva grupal, en La gata de Angora queda prácticamente reducida al personaje de la Marquesa (Silvia) y a dos escenas conversacionales de aristócratas muy distintas al conflicto de intereses general que dominaba las dos comedias anteriores. La sátira aristocrática es, en esta obra, complemento de la evolución de la relación amorosa entre Aurelio y Silvia, mientras que en las otras dos el amor, o bien quedaba relegado al final de la obra, o bien se encontraba ausente.

Silvia se debate entre su voluntad individual y su pertenencia a un núcleo social con convencionalismos asentados. Por una parte, manifiesta su frivolidad ("Por no hacerle esperar he perdido, ¡qué se yo! La tierra y el cielo. He dejado la visita a los pobres, he dejado de ir a casa de la modista" ${ }^{19}$ ) y, por otra, pretende alejarse de la definición de aristócrata que detesta: "No quiero ser un lujo para ti como para todos... ¡Nunca he significado nada en la vida de nadie! He sido siempre la muńeca de lujo..." ${ }^{20}$. Sin embargo, al final del acto II se desvela que la verdadera personalidad de Silvia es la aristócrata y que Aurelio sólo forma parte, como un elemento más, de su ocio y recreo personal ${ }^{21}$. Ella, además, considera ingrato al pintor por no aceptar el rechazo, pues le debe, por encima del

17 Jacinto Benavente, La gata de Angora, en Obras completas, I, pp. 436-437.

18 Ibidem, pp. 438-441.

19 Ibidem, p. 442.

20 Ibidem, p. 444-445.

21 La cartera fue un objeto recurrente en los primeros textos benaventinos como elemento revelador de la vida social y personal de las clases altas y se desarrolló en una escena publicada en Blanco y Negro. Véase Jacinto Benavente, "La cartera", Blanco y Negro, VII, 317 (29/V/1897), pp. 6-7. En La gata de Angora, Aurelio comprueba la importancia que tiene en la vida de Silvia después de ver, en su cartera, que sólo ocupa una línea en su agenda (“de 4 a 5”), junto a la visita a la modista, a los pobres y al teatro. 
cariño, gratitud económica y social ${ }^{22}$.

Por otra parte, la sátira de las clases altas está presente a través de una serie de personajes paródicos que exageran los vicios de la sociedad y ridiculizan el esnobismo y la petulancia. El ejemplo paradigmático es el del Marqués del Suspiro del Toro de El automóvil - Teatro Lara, 19 de diciembre de 1902 — , que la crítica recibió con sumo agrado, pero en las primeras sátiras se encuentran otros secundarios cuyo perfil, aunque no se dibuja con tanta precisión, ofrece un contrapunto cómico a la visión mordaz negativa del conjunto.

En La farándula - Teatro Lara, 30 de noviembre de 1897- la Marquesa Viuda del Robledal, aristócrata murmuradora y frívola, protagoniza varias escenas aisladas de la trama cuyo fin último es provocar la risa del espectador a través de un ridículo que raya en lo absurdo. Se convierten, incluso, en una concatenación de chistes recurrentes a lo largo de toda la comedia, por lo que el personaje adquiere una importancia fundamental en el marco de la sátira. El papel fue interpretado, precisamente, por Balbina Valverde, lo que denota la idea de su perfil característico y, al mismo tiempo, de su importancia en la obra.

En la escena 12 del acto I se la define así: "la infeliz es una buena señora, sin más debilidades que vestirse muy llamativa con trajes de todos los colores del arco iris... En sus tiempos daba muchas reuniones... ¡La flor de lo cursi, pero muy divertidas y con la mayor libertad!... De ahí salieron lo menos veinte bodas" ${ }^{23}$. La caracterización de las mujeres adineradas como casamenteras es recurrente en la obra de Benavente; está asimismo presente en la Marquesa de Palmar de Al natural - Teatro Lara, 20 de noviembre de 1903_, que vive para convenir matrimonios (también interpretada por Balbina Valverde) y en Dońa Flora de Lo cursi, que organiza reuniones de solteros para iniciar relaciones.

La cursilería de la Marquesa Viuda de Robledal se expresa, sobre todo, a través de la comparación con su hija Pepita, empeñada en crecer antes de tiempo y con cierta afición a los refrescos alcohólicos:

22 Jacinto Benavente, La gata de Angora, pp. 459-463.

23 Jacinto Benavente, La farándula, en Obras completas, I, p. 265. 
Marquesa (A Pepita): ¿Por qué te has recogido la trenza? ${ }^{24}$

Pepita: ¡Ay, mamá! Déjame... estoy mejor así.

Marquesa: Qué afán de envejecerte. Como si todo el mundo no conociera, a pesar de que estás muy desarrollada, que eres una niña todavía. Pepita: Pues mira, mamá. El Secretario de don Gonzalo me ha dicho que así parezco hermana tuya. Pero no quiero oírte.

Marquesa: ¿Te ha dicho?... Déjalo, no te lo sueltes ${ }^{25}$.

Esta escena se inserta en el marco conversacional de la parodia y la censura política de forma independiente a ellas y continúa en la escena 1 del acto II con uno de los momentos que la crítica destacó por su comicidad y por la diversión que causó en el público, la embriaguez de Pepita, que vuelve a intercalarse entre las conversaciones de otros grupos de personajes hasta que consigue reunir a todos y cierra la escena ${ }^{26}$.

La parodia de las aristócratas que ridiculizan su indumentaria buscando rejuvenecerse aparece también en Modas - Teatro Lara, 18 de enero de 1901 -

Primera: Sí, señora. El otro día, cuando probaba usted el traje hechura sastre a la de Zorongo...

Tutú: ¡Hechura sastre, con cincuenta años y cincuenta arrobas! Y tiene el valor de decirme: "¿No le parece a usted que me hace algo cocotte este traje?...”.

Primera: Y usted, ¿qué le dijo?

Tutú: ¿Yo? Le di dos azotes, así..., como que le sentaba los faldones ${ }^{27}$.

Sin embargo, la sátira de las clases altas sobresale en el teatro de Benavente a través del tratamiento del amor y del matrimonio, más allá de los conflictos entre las clases o de las frivolidades de sus intereses y preocupaciones.

24 La determinación de la edad según el peinado que lucía la mujer está también presente en Sacrificios (acto I, escena 2).

25 Jacinto Benavente, La farándula, p. 250.

26 Ibidem, p. 272 y $274-275$.

27 Jacinto Benavente, Modas, en Obras completas, I, p. 544. 


\section{Comedias amorosas}

Los problemas amorosos quedaban supeditados en las sátiras de la aristocracia a la crítica mordaz de la frivolidad de las clases altas y a los conflictos de intereses que surgían para mantener las fortunas familiares. La evolución del teatro de Benavente a partir del cambio de siglo (con $\mathrm{La}$ gata de Angora y, sobre todo, tras el estreno de Lo cursi) confirió a sus comedias un nuevo tono, más moderado, que dio paso al protagonismo de las relaciones sentimentales.

En La comida de las fieras Benavente planteó el tópico virgiliano del omnia vincit amor a través de Victoria e Hipólito, cuyo amor había vencido a las fieras y prevalecía por encima de las riquezas y de la hipocresía social (el nombre de Victoria es, por ello, especialmente significativo) ${ }^{28}$. En la escena 4 del acto I los dos protagonistas se plantean si el amor es, en realidad, cursilería o verdad y, a este respecto, narra Victoria su pasado: se casó con Hipólito por conveniencia y tras una decisión reflexionada, pero luego creció en ella el amor por él. La escena 8 del acto II continúa y completa a la anterior, pues ambos describen su amor en términos de pureza y sinceridad mutua. En estos parlamentos defienden una idea excepcional en la dramaturgia benaventina, el matrimonio como fuente de felicidad y no como deber:

VICTORIA: ¿Deberes? ¿Deberes conmigo? Deja esa palabra. Eso quiere decir obligación penosa; algo que se cumple por eso, por deber. Yo no llamo deber a nada de lo que hago por ti...; lo llamo..., ¡qué sé yo! Algo alegre, fácil, gustoso... Yo daría la vida por ti; y no diría que cumplía un deber; diría... ¡que completaba mi felicidad! ${ }^{29}$.

En el resto de comedias y dramas benaventinos el matrimonio era planteado desde varias perspectivas pero ninguna lo aproximaba a la felicidad. Excepto en el caso de Doll en Sacrificios (Teatro Novedades de Barcelona, 19 de julio de 1901) — quien encuentra natural el sacrificio por quien

28 Nótese la importancia de la onomástica femenina en algunas obras benaventinas: Victoria en La comida de las fieras, Angelita en Gente conocida, Imperia en La noche del sábado, Nené en El hombrecito, etc.

29 Jacinto Benavente, La comida de las fieras, p. 326. 
se ama- y en el de Rosario y Agustín en Lo cursi, el matrimonio pesaba como una losa sobre los personajes o era fruto del interés y del respeto mutuo por la conveniencia.

Por ello, de nuevo el raisonneur irónico comenta el amor de Victoria y de Hipólito como insólito en Madrid: "Digo que he visto muchas cosas por esos salones de Madrid... pero dos esposos abrazándose...; porque lo corriente es que abracen, sí, pero cada uno por su lado"30.

Sin embargo, en La comida de las fieras el amor aparece de manera secundaria, aunque la obra concluya con su ponderación por encima del interés. Los dos primeros actos se desarrollan prácticamente en su ausencia y no cobra especial relevancia hasta llegar el cuadro final.

La gata de Angora reflejaba, a través de algunos personajes secundarios, los matrimonios por dinero y la naturalidad en las infidelidades, pero siempre supeditados a la sátira de las clases altas. En la escena 1 del acto II, por ejemplo, se da noticia de la cancelación de la boda entre Conchita Aguado y su prometido porque en el último momento se había descubierto que él estaba arruinado, a pesar de los destinos de los que había disfrutado. La escena 4 del acto II resulta fundamental en este sentido, pues centra en ella la concepción de la mujer adinerada sobre el amor y el matrimonio. Lola convence a Silvia para que rompa sus relaciones con Aurelio, porque el amor pasional, caduco, no suplanta los privilegios de su vida real. Silvia expone así su idea del matrimonio:

Silvia: [...] mi marido no me ha hecho desgraciada.

Lola: Nunca se ocupó de ti...

Silvia: Por eso quizá no me ha hecho desgraciada. Sé que significo muy poco en su vida; que cualquier extraño, cualquiera que al pasar por la calle le mire un momento, le conoce tanto como yo; y no es desvío de su parte; me quiere todo lo que él puede querer; si me quejara sería quejarme de que no es más rico de lo que es... y no me quejo. Él tampoco exige de mí más cariño del que me ofrece; tal vez le molestaría ${ }^{31}$.

Esta idea es similar a las que desgrana el personaje de Isabel en Rosas de

30 Ibidem, p. 328.

31 Jacinto Benavente, La gata de Angora, p. 456. 
otoño, que acepta resignada la indiferencia (incluso el tedio) que ocasiona en su marido, Gonzalo. Frente a estas actitudes de las clases altas se sitúa el amor pasional del pintor Aurelio, que rechaza las normas sociales impuestas en la vida de Silvia y aceptadas por ella.

En las obras de provincias y en las comedias que se representaron en el Teatro Lara la concepción del amor y del matrimonio se somete a la crítica política (como en La farándula, La gobernadora - Teatro de la Comedia, 8 de octubre de 1901 - o El primo Román - Teatro Principal de Zaragoza, 12 de noviembre de 1901 -), a la parodia de personajes rurales (Al natural), o bien a la comicidad y al humorismo de las obras (como en El tren de los maridos - Teatro Lara, 18 de abril de 1902-o El automóvil).

No obstante, de manera simultánea al estreno de estas obras Benavente consolidó su fama ante el público madrileño con tres comedias amorosas cuyo centro era, precisamente, el matrimonio, el adulterio y las pasiones de los personajes: Lo cursi, Amor de amar, El hombrecito y Rosas de otoño. Las tres primeras se estrenaron en el teatro de la Comedia y fueron protagonizadas por Rosario Pino, mientras que la cuarta (que llevó a las tablas María Guerrero en el Español) supuso el cambio en la creación del dramaturgo madrileńo, tras el fracaso del teatro escenográfico de El dragón de fuego - Teatro Español, 16 de marzo de 1903 - o el simbolismo de La noche del sábado.

Lo cursi resulta especialmente relevante tanto por la sátira del esnobismo aristócrata como por el planteamiento amoroso que ofrecía la comedia. José Luis Calvo Carilla explicó la vaguedad del término "cursi":

La etiqueta no poseía una significación unívoca; antes bien, dentro del valor peyorativo que abrigaba, estaba revestida de tal ambigüedad que tanto Unamuno como el autor de Lo cursi podían arrojársela al rostro para reprocharse diferentes debilidades o excesos. [...] El concepto de lo cursi —en atracción paralela a la ejercida por el kitsch en la Europa de entresiglos - mantuvo su vitalidad durante el modernismo aplicado a los aspectos más dispares de la sociedad. [...] El 19 de enero de 1901 Jacinto Benavente estrenaría una comedia, titulada precisamente Lo cursi, destinada a reflejar las múltiples caras de la cursilería social, sin distingos de clase o de formación, así como a corroborar la ductilidad y polivalencia de un término susceptible de 
la utilización más contradictoria ${ }^{32}$.

A pesar de que no es recordada hoy como una de las comedias de mayor relevancia dentro del conjunto de la producción dramática benaventina, Lo cursi fue considerada en la época la consagración de don Jacinto como el gran sátiro moderno. La gata de Angora, inmediatamente anterior, introducía los conflictos amorosos por encima de la parodia, lo que se consolidó en esta comedia a través de la relación entre Rosario y Agustín. A ellos acompańaba un amplio abanico de personajes caricaturescos que representaban lo cursi y el esnobismo en distintos ámbitos.

El papel de raisonneur paródico de Lo cursi lo cumple el Marqués de Villa-Torres, padre de Agustín, personaje similar al del Marqués de Priola de Henri Lavedan, vividor y mujeriego entrado en años. Es él quien, en la escena 4 del acto I, ofrece la definición de lo cursi que fue recogida por Calvo Carilla como explicación paradigmática de la amplitud del concepto en el Fin de Siglo:

La invención de la palabra cursi complicó horriblemente la vida. Antes existía lo bueno y lo malo, lo divertido y lo aburrido, y a ello se ajustaba nuestra conducta. Ahora existe lo cursi, que no es lo bueno ni lo malo, ni lo que divierte ni lo que aburre; es... una negociación: lo contrario de lo distinguido; es decir, una cosa cada día; porque cuando hay seis personas que piensan o hacen lo mismo, ya es preciso pensar y hacer otra cosa para ser distinguido; y por huir de lo cursi se hacen tonterías, extravagancias..., hasta maldades ${ }^{33}$.

Los personajes de esta comedia son tipos caricaturescos sin ninguna complejidad psicológica. Agustín, quien encarna de manera más clara el arquetipo de burgués adinerado esnob, impone la cursilería como fundamento de su pensamiento y de su actitud vital. Desde la escena primera de la obra trata de condicionar el carácter y el comportamiento de Rosario, que contrasta con el suyo por haber sido educada en un ambiente rural alejado de las modas cosmopolitas. Ella, sin éxito, intenta

32 José Luis Calvo Carilla, Concepto estético de lo cursi, Zaragoza, Institución Fernando el Católico, 2004, p. 7-11.

33 Jacinto Benavente, Lo cursi, en Obras completas, I, p. 580. 
mostrarse distinguida y aceptar la modernidad, aunque la desorientan sus propios principios ${ }^{34}$ y los de su tía Flora, paradigma del conservadurismo moral.

Los círculos modernos en los que se mueve Agustín incluyen a su familia, en especial su tía Valentina y sus dos hijas, que viven separadas de su padre por el pacto matrimonial de no molestarse y son felices bajo ese planteamiento. Gasparito, marido de Valentina, es un esnob burgués de ascendente molieresco, pues alberga similitudes muy estrechas con Argan, protagonista de Le malade imaginaire. Hipocondríaco extremado y egoísta convencido, se preocupa únicamente de su bienestar y de su comodidad; no en vano, la diferencia de costumbres con su esposa les llevó a decidir vivir cada uno en un hogar distinto y visitarse a menudo sin interferir en sus respectivas rutinas:

El desarreglo en las comidas me mata. ¡Si pudiera uno vivir sin comer! Es lo que más me preocupa; ahora quisiera ensayar ese tratamiento de moda: el régimen lácteo combinado con uvas; dicen que da grandes resultados. El estómago es el enemigo. ¡Si pudiera uno vivir sin estómago! ${ }^{35}$.

A zaga de este modelo, Rosario y Agustín duermen en habitaciones separadas y esto contrasta con el pensamiento de su tía Flora, que teme por la familia que acaso no lleguen a formar. Este personaje, arquetipo de la casamentera, se comporta como los tipos similares que encarnan la Marquesa de Al natural, la Marquesa Viuda de Casa Molina o Asunción y Esperanza de Los malhechores del bien. De hecho, Flora es el precursor de estas tres últimas y, como ellas, considera que "salva" a las jóvenes que, de otra manera, no hubieran alcanzado el matrimonio (acto I, escena 5). Para ello, organiza reuniones de prometidas, a fin de que intercambien impresiones acerca de de recién casadas, de novios con sus novias escondidas, etc. y en ello reside su principal diversión (acto I, escena 2).

Flora defiende, como Rosario, los matrimonios que actúan como tales en los eventos sociales, mientras que la tía Valentina y Agustín, como 
otros personajes benaventinos, consideran ridículo este comportamiento, pues lo distinguido es la independencia. Esta idea será desarrollada de manera más detallada en Rosas de otoño a través del personaje de Gonzalo, y se relaciona con la definición del propio Agustín sobre cómo debe quererse en el matrimonio, con el cariño de familia y nada más, por lo que es moralmente legítimo tener una amante (acto I, escena 7).

La cursilería en el matrimonio procede de la imitación francesa, del concepto de dualité con el que parodian la moda parisina del adulterio y del divorcio ${ }^{36}$. Lola acuña un término inglés para referirse a las muchachas que entrenan sus virtudes con el objetivo de conseguir marido, el de las "traineras" (acto II, escena 11), lo que se complementa con el esnobismo del lenguaje que encarna el personaje de Lola (acto I, escena 8), a la que la tía Flora llama "la nińa modernista" 37.

Carlos, amigo de la familia, aprovecha la imposición de la cursilería para acercarse a Rosario, de la que está enamorado, pues convence a la muchacha de que Agustín nunca sentiría celos de él, sentimiento considerado cursi. Sin embargo, son los afectos más primitivos del alma humana los que llevan a Agustín a regresar al lado de su esposa y, al final de la comedia, a alejarse de las modas y permanecer en su compañía. Por ello el Marqués concluye de manera metateatral la comedia: "Y ahora que la moral se ha salvado, como en las comedias cursis..." 38 .

La metaliteratura y el metateatro están presentes en Lo cursi a través de la parodia del modernismo. A Félix, escritor, se le considera literato modernista y decadente, lo que contrasta con el casticismo que defienden Flora y el Marqués. Las ideas de Félix traslucen el pensamiento del propio Benavente:

FLORA: Usted es de los míos, Marqués: a la antigua española.

MARQUÉs: Esta juventud se ríe de nosotros.

FÉLIX: ¡Oh! Sí: lo español, lo castizo. ¿Quieren ustedes decirme en qué consiste eso?

MARQuÉs: Para usted, literato modernista, decadente y qué sé yo cuántos motes más, en nada. ¿Usted qué sabe de eso?

36 Ibidem, p. 604.

37 Ibidem, p. 603.

38 Ibidem, p. 631. 
FÉLIX: Sí, en Literatura ya sé en qué consiste: en lo que ustedes llaman vigor; en concluir los dramas a tiros y los cuentos a navajazos; como si todos los días se recogieran docenas de cadáveres por esas calles. Para usted, querido marqués, sé también en qué consiste el casticismo: en estar abonado a los toros y en comer judías estofadas de casa de la Concha. ¡Ah! Y en aplaudir la comedia de anoche: una joya de la literatura castiza. [...]

MARQuÉs: Pero usted es de otro tiempo. Ahora habrá usted observado que la mujer no llora en el teatro. Alguna pobrecilla de la galería. El público selecto sólo tolera el arte como bufón que divierta; si pretende conmover, lo llama cursi; si pretende hacer pensar; latero. ¿o es ésa la palabra escogida? ${ }^{39}$

Félix defiende, también, la mixtura genérica y ha escrito una obra nueva que no es poema, ni novela, ni historia. Los prólogos a las obras modernistas son también parodiados; Félix afirma la naturaleza de su obra en el "peristilo" (acto III, escena 1) y en esta misma escena define su pensamiento literario: "Desperdiciar todo lo que no existe en el momento actual, como eternizar lo efímero, fijar lo fugitivo, engrandecer lo diminuto. Eso debe ser el arte, el arte nuestro: el actualismo; no hay otro arte posible" 40 .

Félix se encuentra, así, entre el pensamiento de Benavente y la propia parodia del Modernismo, lo que no contrasta con sus artículos periodísticos, donde esta contradicción se observa con cierta frecuencia.

Lo cursi es, pues, una comedia amorosa enmarcada en la parodia de las modas aristocráticas. El sentimentalismo es mayor que el de las primeras sátiras, pero todavía mantiene la burla, aunque con carácter más ligero y menos hiriente que en La comida de las fieras, La farándula o Gente conocida.

La transición a la comedia amorosa que eclipsa la sátira se producirá con El hombrecito, estrenada en la Comedia dos años después de Lo cursi (fue, además, la última obra de Benavente que Rosario Pino interpretó en esta sala). En ella se continúan algunas ideas de las obras anteriores, pero se supeditan a la evolución del personaje de Nené, que nace como

39 Ibidem, p. 579.

40 Ibidem, p. 617. 
arquetipo de la rebeldía (similar a Angelita de Gente conocida o a Victoria de La comida de las fieras), mas termina aceptando su condición social (como Silvia en La gata de Angora).

La cursilería y la distinción están presentes en esta última dentro del ámbito del matrimonio, donde se defiende que la mujer desconozca el pasado de su marido y no cuestione su comportamiento (acto I, escena 1). Por otra parte, Nené y Casilda describen en la escena 2 del acto III los convencionalismos sociales que se imponen en la elección de un marido, donde los candidatos se conocen desde el primer baile y no se puede escoger a miembros de otros círculos o clases (lo que Benavente había planteado previamente en la carta XII de la serie primera de sus Cartas de mujeres). Los bailes y los eventos sociales serán escenario de la mayoría de actos de comedias benaventinas (Gente conocida, La comida de las fieras, La farándula, La gobernadora, Rosas de otoño, Al natural, El automóvil).

El matrimonio entre Pepita y Carlos, acordado por las dos partes, genera conflictos por la dote de Pepita entre su madre, la Marquesa de Cańaverales y Castrojeriz, padre de Nené y Carlos. La Marquesa es similar a otros personajes benaventinos con el mismo título nobiliario y encarna la sátira de la moral de intereses aristocráticos. Carlos, firmemente convencido de la decisión que ha tomado, contrasta con el pensamiento de Nené, que entiende el amor como fundamento del matrimonio:

CARlos: ¿Tiene algo de particular que se trate en serio la cuestión de intereses? ¿Te parece poco poético? Menos poético es vivir de cualquier manera; tienes que convencerte: casi todas las faltas de poesía provienen de la falta de dinero.

Nené: No me creas simple soñadora. Me asusta la pobreza tanto como a ti, como a cualquiera. [...] Cuando yo sé que hay criaturas humanas que mueren de hambre y de frío y que ven morir a sus hijos, todo lo disculpo. [...] Pero cuando la suerte ha sido generosa con nosotros, cuando nos permite el lujo de vivir con la conciencia tranquila, sin hacer traición a nuestros sentimientos..., entonces no hay disculpas para el que engaña, para el que se vende, como tú vas a hacerlo ${ }^{41}$.

41 Jacinto Benavente, El hombrecito, p. 47. 
La postura de la protagonista queda resumida en la escena 5 del acto II, en la intervención más relevante en la comedia: "Parece que todas las relaciones en sociedad han de limitarse a un solo objeto: combinaciones matrimoniales o intrigas amorosas; [...] el verdadero carińo, que todo lo arrastra, que ni previene ni calcula, ¿dónde está? [...]. Un cariño que todo lo vence, que a todo se sobrepone..." ${ }^{42}$.

El raisonneur de la obra - don Juan Manuel, abuelo de Nené- aconseja a los prometidos que reflexionen antes de contraer matrimonio, pues la mayoría se convierten en desgraciados (acto I, escena 2). Este personaje será el que defina el apelativo de "hombrecito" aplicado a la protagonista: "Desde chiquitina... Una cabecita muy sentada siempre... La llamábamos el hombrecito...". La originalidad de este personaje radica en ser el primer abuelo presente en el teatro benaventino y creado, además, desde una perspectiva dual, al mismo tiempo humorística y razonadora.

El amor entre Nené y Enrique es el origen del pensamiento de la protagonista sobre el matrimonio y se plantea en el acto I de acuerdo con su definición de "hombrecito", en contra de los convencionalismos sociales pero, conforme avanza la comedia, evoluciona hacia una posición más moderada. Enrique muestra su honradez confesándole a Nené su estado (es un hombre casado en otro país) y decide marcharse para no comprometer el honor de la muchacha (acto I, escena 8), a pesar de que regresa en el acto II $y$, tras hablar con Carlos, acuerda con éste volver a separarse de Nené. Estos vaivenes en la conducta del personaje fueron criticados en la primera recepción de la obra, pues ni el público ni la crítica aceptaron que se produjesen las mismas situaciones en los dos primeros actos con un final idéntico.

Sin embargo, en el acto III Nené empieza a cambiar de sentimientos: ama a Enrique, pero se debate entre su amor y lo que su familia y su amiga Casilda le aconsejan respecto a su nombre y a su posición social (acto III, escena 2). En la escena final de la comedia Enrique le propone que se marchen juntos, tras explicarle lo que supondría para las normas que les han sido impuestas, pero entonces a ella le falta valor y niega el apelativo de "hombrecito", pues su corazón carece de fuerza para luchar contra todos (acto III, escena 7).

La perspectiva de esta obra sobre el amor, el matrimonio y las infide-

42 Ibidem, pp. 58-59. 
lidades es notablemente más moderada que la de las comedias anteriores y camina hacia el planteamiento de Rosas de otoño, de ideología más conservadora que El hombrecito.

Amor de amar, muy diferente de las dos anteriores, satiriza a los "amantes del amor" en el marco de la aristocracia del siglo XVIII. La obra, cuyos moldes compositivos distan mucho de los de las comedias satíricas y las amorosas anteriores, fue estrenada en el teatro de la Comedia el 24 de febrero de 1902.

La comedia se centra en el personaje de la Marquesa Rosalinda, aristócrata que, tras una temporada intensa en la capital, ha decidido marcharse al campo para poder descansar y recuperar su salud (en la línea del tópico de "menosprecio de corte y alabanza de aldea" de obras como Al natural). Alrededor de ella circulan una serie de personajes cómicos que ofrecen distintas perspectivas acerca del amor y del amante: Lauro, Rodrigo, Celia y Octavio.

Lauro, filósofo metafísico que linda con el tipo del raseur protagoniza, junto a Rosalinda, los parlamentos más extensos sobre las relaciones amorosas, el matrimonio y el adulterio. Abandonado por su mujer, se lamenta de su situación y analiza con la Marquesa los motivos de elección y separación de un matrimonio (acto I, escena 4). Con todo, a diferencia de otros maridos engañados acepta su situación con resignación y no piensa en la venganza, barajando así la posibilidad de que en el engaño femenino la culpa la tenga el marido, pues no cumple las expectativas que la mujer había depositado en el casamiento ${ }^{43}$.

Lauro explica el concepto de "intelecto de amor" (remitiendo a la Vita Nuova de Dante) que Benavente había utilizado en un texto publicado en Revista Nueva en 1899, donde un enamorado ensalzaba su amor por encima de los defectos de su amada, remitiendo al verso "lo sé, pero ¡es tan hermosa!" de la Rima XXXIX de Bécquer ${ }^{44}$. En Amor de amar se define como:

LAURO: El amor, amor; el amor vulgar que apetece y desea, ciega el entendimiento; el entendimiento sin amor, en cambio, seca el cora-

43 Jacinto Benavente, Amor de amar, en Obras completas, I, p. 844.

44 Jacinto Benavente, "Intelecto de amor", Revista Nueva, I, 14 (25/VI/1899), pp. 635-636. 
zón; solo es completa ciencia de la vida la que entiende y ama ¿Veis a un ser indigno de amor en su apariencia miserable? No apartéis de él los ojos, no le huyáis; consideradle atento; estudiadle, entendedle; la luz con que lucháis contra las sombras será al mismo tiempo calor contra la frialdad [...] ¡Todas dignas de amor, si las amamos con entendimiento! ${ }^{15}$

La Marquesa se enamora de todos cuantos se acercan a ella con requiebros y galanteos, pues su verdadera inclinación es el amor mismo ${ }^{46}$. El siguiente personaje, el capitán Rodrigo, mezcla del soldado fanfarrón y del provincianismo vulgar, trata de refinarse al lado de su prima, la Marquesa, pero su naturaleza se lo impide. Por ello, protagoniza situaciones atrevidas que fueron reprobadas por la crítica, aunque divirtieron al público:

RoDRIGo: Yo no tengo en mi cuarto más que un libro que trata de las diferentes posiciones...

Rosalinda: ¡Primo!

Rodrigo: No te asustes. No me has dejado concluir. De las diferentes posiciones de un ejército beligerante. Es un libro de táctica ${ }^{47}$.

El tercer personaje, Celia, amiga de Rosalinda, es el arquetipo de mujer coqueta y frívola que centra su vida en la diversión que le aportan sus escarceos amorosos. En este caso huye de Octavio, el amante apasionado y celoso que la persigue sin cesar, y representa la hipocresía de la aristocracia:

Yo no sé cómo otras mujeres pueden llevar una vida de intrigas sin verse nunca en trance tan apurado. Tú sabes lo poco que yo he dado que hablar, mi exceso de prudencia; y la primera vez, la primera, puedes creerlo, que me decido a permitir galanteos asiduos, doy la preferencia a un loco frenético que será capaz de comprometer mi reputación, ¡quién sabe!..., de matarme ${ }^{48}$.

45 Jacinto Benavente, Amor de amar, p. 845.

46 Ibidem, pp. 845-846.

47 Ibidem, p. 848.

48 Ibidem, p. 856. 
Amor de amar es una comedia original en la producción benaventina. Tanto por la época en que se enmarca como por la estructura del argumento y las distintas perspectivas que ofrece del amor desde un punto de vista teórico se aleja del espíritu práctico que dominaba las sátiras anteriores. La obra pareció a algunos demasiado ligera; a otros, el acto I pesado en comparación con el siguiente, y no satisfizo a la opinión general.

Rosas de otoño será la consagración de la comedia amorosa benaventina, cuyos elementos había ensayado en estas obras anteriores, ahora recopilados para granjearse el éxito de crítica y público en el Teatro Español.

\section{LA VIDA DE PROVINCIAS}

En contraste con el cosmopolitismo de las sátiras de las clases altas y de las comedias amorosas de Gente conocida, La comida de las fieras, Lo cursi, La gata de Angora, El automóvil, La princesa Bebé, El hombrecito, Amor de amar o Rosas de otoño Benavente se acercó a la vida de provincias en algunas de sus comedias y, en la mayor parte de los casos, con una mirada política. Los asuntos que en ellas trató guardaban estrecha relación, además, con la sección "Arańazos y bufidos" que publicó en El Globo, los artículos de mayor mordacidad entre toda su producción periodística.

Dos de ellas, La farándula y Al natural se estrenaron en el Lara y por ello mantienen la estructura en dos actos propia de las obras que allí representaba, mientras que La gobernadora, dedicada a Rosario Pino, se llevó a las tablas por primera vez en la Comedia y El primo Román en el Principal de Zaragoza, divididas en tres actos. La razón de su exclusión en el siguiente epígrafe reside en la temática común y en los paralelismos notables que se hallan entre ellas, por lo que conforman un grupo independiente dentro del conjunto del teatro benaventino de esta primera década.

Exceptuando El primo Román, que tiene lugar en un pueblo de Castilla, La farándula, La gobernadora y Al natural se desarrollan en Moraleda, capital de provincia y espacio de ficción creado por Benavente como reino de la hipocresía moral, del caciquismo y de las falsas apariencias. En este sentido, poco se diferencia de otros espacios inventados como Suavia ( $L a$ noche del sábado y La princesa Bebé) o el propio Madrid en el que se desarrollan otras sátiras; el único elemento que las distancia es la presencia del 
cacique y de la vida política, ausente en las comedias cosmopolitas. Rubio Jiménez estableció el paralelismo entre Moraleda y la Vetusta clariniana, la Marineda de Emilia Pardo Bazán o la Orbajosa de Doña Perfecta, "cuya versión dramática se había estrenado no hacía mucho. Las similitudes con la obra galdosiana son incluso de detalle. Como en ella, por ejemplo, existen personajes capaces de tomarse la justicia por su mano, mediante bandoleros pagados" ${ }^{49}$. El contenido simbólico del nombre Moraleda, que se relaciona con multitud de artículos en los que Benavente fustigó la falsa moralidad que reinaba en la alta sociedad, servirá al dramaturgo madrileño de amplio escenario donde convergen asuntos dispares presentes ya en escenas y obras anteriores.

Si bien la estructura de La farándula sigue un esquema compositivo similar al de Gente conocida y La comida de las fieras, dista de ellas en el planteamiento temático y en la creación de los personajes, pues el epicentro de la comedia deja de ser el conflicto de intereses y de clases para dar paso a la parodia de la vida política.

La aristocracia está todavía presente en esta obra pero como complemento del conjunto social provinciano, conformado por tipos: el político, el raisonneur irónico, la aristócrata frívola, los criados rústicos, el jovencito impertinente, etc. La clase social, que representa la Marquesa, se funde con el resto de mujeres de Moraleda en su actitud murmuradora y a todas se las enmarca bajo el apelativo de "ojos de Moraleda atisbadores y devoradores de vidas ajenas" $"$.

Las líneas de análisis de esta comedia fueron apuntadas por Rubio Jiménez $^{51}$, por lo que este apartado se limitará a desarrollar algunas de ellas y señalar otros aspectos de interés teatral.

La metáfora de la vida política a guisa de "farándula", que actúa por los distintos lugares como miembros de una compañía cuyo discurso es ficticio, se explica en la escena 12 del acto I: "Es que me canso de hacer la misma comedia. Esta temporada de provincias me ha desengañado por completo. ¡Siempre la misma farsa! ¡El eterno discurso! [...] Y así andamos de lugar en lugar, como la antigua farándula” ${ }^{2}$. Además, esta hipo-

49 Jesús Rubio Jiménez, op. cit., p. 194.

50 Jacinto Benavente, La farándula, p. 282.

51 Jesús Rubio Jiménez, op. cit., pp. 194-196.

52 Jacinto Benavente, La farándula, p. 266. 
cresía en el discurso político se relaciona con el significado del topónimo, puesto que Hinestrosa llega a Moraleda "a predicar la Moralidad" 53 . Con estas palabras cierra el acto I, lo que ya había anunciado en la escena 8 , donde afirma que su lema es "moralidad, moralidad" 54 expresión que, en realidad, no es sino disfraz del oportunismo político: "Mi partido no lucha por las ideas políticas; está organizado de suerte que puede sumarse en cualquier momento con cualquier otro partido..., con el primero que suba"55.

Rubio Jiménez advirtió uno de los elementos más interesantes de La farándula: los paralelismos entre el personaje de Aurelio y el propio Benavente, que no se advierten de manera tan clara en ninguna de sus otras obras:

Benavente se mete en este personaje, moraliza desde él. Aurelio tiene rasgos del "raisonneur" del teatro anterior, pero sobre todo aglutina los de los escritores de la "gente nueva". [...] Ansúrez aplica a su compañero algunos de los adjetivos que con más frecuencia se utilizaban para referirse a Benavente: "mefistofélico", falto de corazón. El estreno de La farándula coincide con el alejamiento de Benavente de estos escritores ${ }^{56}$.

A pesar de que Benavente participó de las ideas dramáticas de la "gente nueva" sobre todo en sus primeras piezas, no creo que en 1897 comenzara a alejarse de este grupo; primero, porque quizá no perteneció nunca a él, puesto que su caminar independiente y, en cierto modo, cambiante, lo situaba en varios frentes, a veces coincidentes y otras discrepantes; en segundo lugar, porque todavía mantendría esta postura dramática unos años más. Quizá por ello afirma Aurelio: "Para usted [Guadalupe] soy un joven-viejo, traidor al amor y a la juventud. Para usted [Gonzalo], un poeta, un soñador y casi un espía, traidor a un partido" 57 .

El paralelismo entre Aurelio y Benavente va más allá de su caracterización externa como raisonneur y llega, incluso, a la descripción de su

53 Ibidem, p. 270.

54 Ibidem, p. 256.

55 Ibidem, p. 257.

56 Jesús Rubio Jiménez, op. cit., p. 195.

57 Jacinto Benavente, La farándula, p. 278. 
pasado teatral:

Yo no tenía más patrimonio que dos o tres dramas, errantes de continuo por todos los teatros de Madrid, y una porción de versos y de leyendas, donde ponía yo toda mi vida de entonces, mis ilusiones, mis esperanzas. ¡Pero eran tan mías y tan pequeñas, que a nadie le interesaban! ${ }^{58}$

En 1897 Benavente había escrito, precisamente, varias leyendas ${ }^{59}$, su libro de poesía Versos — que aglutinaba textos escritos en sus cuadernos de años atrás con otros ad hoc-y tres dramas estrenados (El nido ajeno, Gente conocida y La farándula) además del Teatro fantástico, Cartas de mujeres y alguna otra obra, inédita y desconocida hoy, que databa de los ańos ochenta.

En La gobernadora (cuatro años posterior) la vida provinciana está más presente a través del lenguaje vulgar que en La farándula, pues la aparición de personajes de clases bajas es mayor que en aquella, a pesar de que los criados representan estos tipos teatrales (en la escena 1 del acto I contrasta el léxico de Miguela y Nicanor frente al de los señores y en la escena siguiente se parodia el habla rural por medio de la aféresis — "ministración" por "administración" con el juego de palabras que conlleva con "ministro"- - etc.). Damián, dueño de un café y la Menéndez, actriz, son quienes encarnan la incorrección lingüística; en especial esta última (parodia del género chico), que se opone al carácter ridículo de Garcés, empresario de la compañía empeñado en corregirle:

Menéndez: Por supuesto, en cuanto pasen estos días de feria, yo no le doy a este tío más de cuatro pesetas. ¡Seis pesetas por un cuartucho con una sola ventana a un patio y una cama que yo sola no cojo!... GARCÉs: ¡Pero cómo hablas, mujer; cómo hablas!

Menéndez: ¿Pues qué he dicho?

Garcés: Que no sabes Gramática. ¡Una cama que yo sola no cojo! En primer lugar, no se dice "cojo", se dice "quepo"; y hay que decir "una

58 Ibidem, pp. 287-288.

59 En el Archivo Histórico Nacional se conserva un buen número de manuscritos de juventud de Jacinto Benavente que aglutinan veinticinco obras de teatro, dos libros de poesía (uno de ellos de haikai), dos novelas y cuatro leyendas, estas últimas escritas entre 1879 y 1881. 
cama, en la cual, o en la que"... ${ }^{60}$.

No obstante, la originalidad de La gobernadora radica en ser la primera obra benaventina que trata el asunto del caciquismo. Baldomero Remolinos, cacique de Moraleda, trata de chantajear a su secretario para que abandone su puesto, pues se ha rebelado contra él (acto II, escenas 6 y 7). No lo consigue gracias a los ardides de éste con Josefina, la esposa del gobernador, con la que mantiene relaciones. La sátira del cacique parte de su origen como revolucionario liberal, amén de llevar el nombre del general Espartero y, antes de convertirse en el tirano de Moraleda, defender la libertad con cánticos del himno de Riego. Como terrateniente enriquecido defiende la falsa moralidad que representa su esposa, Doña O, personaje similar al de la Marquesa de La farándula o a la de cualquier murmuradora benaventina. Esperancita, hija de ambos, encarna el carácter contrario al de Angelita de Gente conocida, pues esta es considerada también el mejor partido de Madrid y a aquella la llamaban "la niña de oro" ${ }^{1}$ (a los pretendientes de Angelita los denominaban, en la misma línea, “cazadores de oro”). Como contrapunto, la aristocracia en esta obra (a través de la Marquesa de Torrelodones) representa la actitud liberal de la capital ante el teatro y las relaciones amorosas y reacciona contra el conservadurismo moralediense.

Por otra parte, Benavente refleja la sociabilidad teatral relacionada con la política que censuró en algunos de sus artículos, pues el teatro se convertía en maniobra de gobierno, religiosa o de interés personal, en detrimento de su valor artístico, ya que los admiradores o detractores de una obra respondían a criterios oportunistas o de postura política y no a juicios literarios. Obscurantismo, drama simbolista de ideas (cuya protagonista es la personificación de la ciencia, como explica el empresario) es rechazado por los conservadores y admirado por los liberales, de manera que se establece una frontera entre la modernidad teatral y política - de carácter europeísta - y el tradicionalismo castizo provinciano (otra Querella de Antiguos y Modernos).

El papel de la mujer es, en esta obra, distinto de las anteriores, pues muestra la superioridad femenina en el matrimonio a través de Josefina y

60 Jacinto Benavente, La gobernadora, en Obras completas, I, p. 684.

61 Ibidem, p. 691. 
Santiago, los gobernadores. Aquella domina el comportamiento de este, que se presenta como espíritu pusilánime e influenciable y el triángulo amoroso Santiago-Josefina-Manolo acaba convirtiendo en gobernadores a estos últimos y a Santiago en la voz que transmite sus pensamientos.

El planteamiento de Al natural es muy distinto del de La gobernadora, pues la cuestión política deja paso a la amorosa y construye una comedia romántica sencilla tanto dramática como psicológicamente. Los personajes característicos (en especial, la Marquesa del Palmar y Don Demetrio) son lo más interesante de la obra, interpretados por los primeros actores del Lara: Balbina Valverde y José Santiago.

La idea de la obra es expresada por la Marquesa al final del último acto, como en la mayor parte de comedias estrenadas en esta sala: "Y al natural... que es como se conoce bien a la gente"62. Joaquín, aristócrata cosmopolita altanero y esnob termina enamorándose de Pilar, muchacha sencilla de provincias (Moraleda) alejada de la cursilería y de la elegancia de la capital. No obstante, para que el amor surja es necesario que cada uno de los amantes se halle en su medio, "al natural", donde no desentonen con el entorno. Para ello se contraponen en los dos actos que conforman la comedia la vida de la ciudad y la de la provincia: el primero se desarrolla en Madrid y el segundo en una finca de campo.

De esta manera, Benavente juega con la perspectiva de los personajes por primera vez en su dramaturgia, pues el protagonismo de los madrileños en el acto I, en el que el espectador ve a través de éstos, contrasta con el de la vida campestre del II, en el que predomina el tópico guevariano.

La Marquesa, cuya función social es ejercer de casamentera, proyecta la boda de su sobrino con Pilar, una provinciana:

Llevo arregladas lo menos, una... dos... cuatro... ¿qué más? Mi primo Carlos con mi cuñada Emilia... Las dos doncellas, la una con el cochero y otra con el ordenanza de mi cuńado el general... Las dos chicas de Cabanillas con los dos pasantes de Espinosa; total, doce. ¡Jesús! ¡Esta hace la trece! Yo no creo en estas cosas; pero de tanto oírlas entra una en aprensión. ¡Ya estoy preocupada! No; yo caso antes a cualquiera, para que sea la catorce. ¿̇ quién caso si no

62 Jacinto Benavente, Al natural, en Obras completas, II, p. 248. 
me queda nadie? ${ }^{63}$

El objetivo del matrimonio, empero, no es otro que el económico:

Marquesa: [...] La muchacha es preciosa. Aunque siempre ha vivido en Moraleda, y más en el campo, ha viajado bastante, ha estado en Madrid algunas temporadas, en París, creo que en Italia... Sabe francés, inglés, no toca el piano; está muy bien educada.

Eufemia: ¿Hija única?

MARQuesa: Sí. El padre tendrá unos diez millones de capital ${ }^{64}$.

La presencia del esnobismo aristocrático a través de la inserción de frases o expresiones francesas, que será fundamental en Rosas de otoño es representada a través del personaje de don Paco: "Ya verá usted la casa de las de Inestrilla. C'est quelque chose de chic... Todo arte moderno. [...] La nuance, la nuance partout... El matiz, la irisación [...] algo que flota, que se desvanece... frou; frou... todo frou, frou" ${ }^{65}$.

El mundo rural contrasta con el aristocrático a través de la figura de don Demetrio, cuya naturalidad en la expresión no es bien aceptada por los cosmopolitas, que rigen su comportamiento de acuerdo con las leyes de lo cursi:

Marquesa: Siéntense ustedes. ¿Vienen ustedes de algún teatro?

D. Demetrio: No. ¡Los teatros concluyen tan tarde! Hemos estado haciendo tiempo en el hotel... Aburridos... Esta se dormía...

Olalla: ¡Demetrio!

D. Demetrio: La falta de costumbre. Como ahora venimos del campo y allí se acuesta uno con las gallinas... [...] La otra noche fuimos a un teatro de esos por horas, nos dio la mala idea de sacar billetes para toda la noche, y por aprovechar, nos quedamos hasta la última... Y crea usted que hicimos el buey; porque nos caíamos de sueño y estuvimos dando cabezadas.

Olalla: ¡Demetrio!

63 Ibidem, pp. 195-196.

64 Ibidem, pp. 192-193.

65 Ibidem, pp. 208-209. 
Anita: (Aparte). ¿De dónde habrá sacado mi tía esta familia? ${ }^{26}$

Este personaje, en cambio, en su entorno es apreciado por su perseverancia y su ambición modesta (acto II, escena 5) y por ello ya no divierte a los aristócratas (acto II, escena 8); de allí que su hija Pilar, que en Madrid les parecía insulsa y apocada, en el campo se convierta para Joaquín encantadora y resuelta (acto II, escena 11).

Por otra parte, Al natural introduce al comienzo de la obra una parodia del modernismo a través de la lectura de la Marquesa, a la que regalan un libro que responde a esta estética y que recuerda, aunque de forma satírica, a las acotaciones iniciales de los dramas de D’Annunzio:

Marquesa: [...] Ese triunfante atardecer de un día glorioso, todo belleza en exquisito concento de intelectualidad y emoción”. Lo de atardecer no me hace mucha gracia... Pero, en fin, peor sería que hubiese dicho noche cerrada... A ver más adelante... (Leyendo). "Era un atardecer de amatista; en el cielo acuarela, un sol moribundo se desangraba como gladiador vencido... La Princesa Melinita —oro, nácar y rosas - reía violeta a sus ensueños grises. En el jardín de un verde líquido...”. Por si acaso, le dejo en el verde líquido. Esta Princesa Melinita me pone en cuidado ${ }^{67}$.

El contraste entre esta burla del Modernismo y el prólogo de La noche del sábado es notable y responde a la variabilidad de planteamientos benaventinos acordes con las distintas salas en las que estrenaba y con el público que acudía a ellas.

El primo Román, única comedia ambientada en provincia que no se estrenó en la capital espańola sino en el Teatro Principal de Zaragoza el 12 de noviembre de 1901 , otorga un protagonismo mayor a los personajes rurales que en obras anteriores, pues éstos no funcionan únicamente como representantes de un sector social parodiado (como en el caso de los criados de La farándula, Damián en La gobernadora o de Demetrio y Olalla en $A$ l natural), sino que se convierten en uno de los motores de la acción y se mezclan en el conflicto de intereses de las clases altas.

66 Ibidem, p. 203.

67 Ibidem, p. 185. 
La obra se desarrolla a través de las relaciones que rodean a Román, candidato a diputado por el pueblo en el que tiene lugar la acción y la búsqueda de votos por parte de éste para lograr el acta. Amalia, viuda arruinada con un hijo, pretende casarse con él para mejorar su situación económica, y Cristeta, hija bastarda del marido fallecido de la dueña de la finca, Salomé, se enamora de él por sus dotes oratorias. Por otra parte Romualdo, administrador de la casa, busca unir a su hijo Luciano (al que ha mandado a estudiar) con Cristeta para heredar la fortuna de Salomé.

Toda esta red de intereses funciona como un paréntesis en la vida política de Román en la capital (paralelo, en el fondo, al propio planteamiento de la comedia, alejada brevemente de los estrenos benaventinos de Madrid). No obstante, Román, a pesar de ser el eje central de la obra, no determina los acontecimientos y su personalidad apenas está dibujada. Todos los personajes, sencillos en su composición, sirven para poner de manifiesto la compra de votos por parte de los políticos, ya sea desde la persuasión económica y laboral (como en el caso de Romualdo o de otros miembros del pueblo castellano) o bien sentimental (como en el de Cristeta o Amalia).

La crítica política es menos compleja que en las otras piezas, el carácter metateatral permanece ausente y la sátira de los personajes resulta menor; tampoco ambientan la acción el conjunto de secundarios irónicos habitual en otras parodias benaventinas de la vida cosmopolita o de provincias. La función de raisonneur, que en El primo Román cumple Magín (nombre que llevará después otra comedia benaventina, Don Magin el de las magias), dista mucho del Aurelio de La farándula, pues el sentimentalismo del anciano, que vive por el cariño de Cristeta, eclipsa su distanciamiento analítico, a pesar de que cierra la comedia de este modo:

Magín: Déjale. Te deja porque es ambicioso y va a luchar allá, como ha luchado aquí, engañando a los unos, implorando de los otros, comprobando y vendiéndose. Quizás logre lo que ambiciona: será célebre, será ministro, será todo lo que hay que ser. No importa. [...] Tu cariño fue un sueño, pero el sueño de un alma buena... Y esos sueños... ¡Espéralo, hija mía!... Esos sueños resucitan en el cielo ${ }^{68}$.

68 Jacinto Benavente, El primo Román, en Obras completas, I, pp. 834-835. 
Este final, muy distinto del de la sátira de la aristocracia primera, se acerca a la dulcificación de $A l$ natural y al de otras obras posteriores (especialmente desde Rosas de otoño). Por otra parte, se relaciona a contrario con el de los dramas de ideas Sacrificios y Alma triunfante — Teatro de la Comedia, 2 de diciembre de 1902 — en el componente simbólico de la muchacha joven, idealizada como un alma pura incorruptible. En este sentido, cobra especial importancia la iluminación del final del acto II, en el que se oscurece la escena lentamente tras la marcha de Román (escena 15) y la tristeza de Cristeta, a la que acompaña una profusión de truenos y relámpagos; se trata de la única ocasión en que Benavente introduce elementos escenográficos relacionados con la meteorología, y los cambios de luces son también infrecuentes en su producción dramática (uno de los pocos ejemplos es el final de Gente conocida).

El menosprecio de corte y alabanza de aldea surge desde la perspectiva opuesta a Al natural: en El primo Román es su protagonista, Salomé, de clase alta, quien detesta la capital por los vicios que la rodean y los sufrimientos que ocasiona ${ }^{69}$.

Las comedias de provincias suponen un primer acercamiento a los personajes rurales que Benavente continuará después en sus dramas ${ }^{70}$. En la ambientación y en la creación de algunos tipos se alejan de las sátiras de las clases altas que había estrenado en su juventud, pero la presencia de aristócratas establece un nexo común con aquella etapa, aunque su papel sea secundario. La parodia política y el caciquismo surgen como nuevos asuntos en estas obras y evolucionan hacia comedias amorosas a la par que sus argumentos cosmopolitas, donde la ironía se dulcifica y asoma el sentimentalismo.

\section{Los ESTRENOS DEL LARA}

Las comedias representadas en el teatro Lara, aunque mantienen los principios benaventinos de sus composiciones previas, conforman desde el punto de vista genérico un grupo aislado, pues la sala imponía ciertas

69 Ibidem, p. 781.

70 Véase a este respecto Mariano de Paco Moya, "Jacinto Benavente y el drama rural", Cuadernos del Lazarillo: Revista Literaria y Cultural, 26 (2004), pp. 25-29. 
condiciones de comicidad a las obras donde no cabían planteamientos como los de Gente conocida, La comida de las fieras, La gata de Angora, etc., en las que la sonrisa poseía un cariz amargo.

Todas ellas se estructuran en dos actos (Al natural, El tren de los maridos y El automóvil), su duración es menor a la de otras obras, la presencia de personajes tipo se acentúa y desaparecen los conflictos morales o psicológicos. Son, pues, comedias ligeras (cercanas al sainete) donde el fin último es la propia comicidad; el chiste cobra una importancia sustancial y el desarrollo de ideas es mínimo. En la mayor parte de ellas (El tren de los maridos, El automóvil) los actores se dirigen al público al final de la obra pidiendo el aplauso, lo que se aleja notablemente de los desenlaces de las otras comedias.

El tren de los maridos posee un interés especial dentro de este corpus estrenado en el Lara, pues se trata de la única obra que responde a las características del género vodevil. Con un alto componente metateatral, la obra se configura como una posible creación de dos de los personajes, que escriben para teatros de género chico piezas similares. El primer acto, que sorprendió a la crítica por estar protagonizado únicamente por mujeres, ofrece una perspectiva de las novedades que se incorporaron en el teatro de la generación del cambio de siglo y de la anterior, cuyos planteamientos se contraponían y se relacionaban con la evolución de los convencionalismos sociales y morales.

Emilio y Eduardo, los maridos de Felisa y Carmen, respectivamente, colaboran en la creación de comedias humorísticas que no son del agrado de la madre de la segunda, Jacoba, cuyo esposo triunfó con dramas morales $^{71}$. Las obras que escriben Eduardo y Emilio son vinculadas con los géneros teatrales parisinos, despreciados también por Jacoba, pues París era la capital de la libertad y el libertinaje. Las generaciones anteriores y de pensamiento más tradicional (que se oponen al esnobismo aristócrata o altoburgués) rechazan a priori la fama de las ideas francesas:

Jасова: Yo no sé por qué se me figura que París no había de gustarme. ¡Aquellas costumbres tan libres! Y era que mi pobre Remigio tenía horror a todo lo francés. No podía ver una comedia traducida: como todo lo suyo fue siempre original y tan castizo... [...] Usted

71 Jacinto Benavente, El tren de los maridos, en Obras completas, I, p. 930. 
conoce sus comedias, sin esas cosas que se ven ahora por los teatros. Cuarenta y ocho comedias dejó escritas, y en ninguna verá usted que una mujer falte a su marido; sólo en una se inicia la falta; pero la esposa vuelve a la senda del deber antes de la mitad del segundo acto, y del segundo al tercero, salva a su marido de la ruina y se sacrifica por su padre ${ }^{72}$.

El teatro de Remigio responde al sistema de la pièce bien faite de contenido amoroso moralista, que es parodiado por Benavente a través de las palabras de la mujer, pues el esquema de la evolución de la acción previamente acordada con la organización de los distintos actos y el tono doctrinal lo aleja del realismo defendido por la gente nueva. Por ello Jacoba se lamenta de que los jóvenes califiquen su teatro de "ńoño y cursi" y Carmen ratifica el aburrimiento que éste causa en los espectadores ${ }^{73}$. A la temática ligera de las obras se une la degradación de la técnica actoral declamatoria que es, siempre a juicio de Jacoba, la única verdaderamente dramática:

JAСовA: [...] tampoco hay actores capaces de interpretar esas obras tan delicadas. ¡Si ustedes hubieran conocido a la Benítez! ¡Qué actriz! ¡Lástima que se casara tan pronto y se retirara del teatro! Se casó con un título. ¿YY la Rosales? ¡Qué damita joven! ¡Cómo lloraba! Como ya no llora nadie. ¿Y aquel Molinero? ¡Qué galán! ¡Qué buena figura! Bordaban las comedias ${ }^{74}$.

Benavente alude, además, al matrimonio de las actrices, que las retira de los escenarios, motivo que ya había criticado en más de un artículo ${ }^{75}$.

El acto I prepara la confusión vodevilesca del II en torno al tren de los maridos, el transporte en el que viajan Emilio, Eduardo y Ángel desde Madrid hasta el pueblo para reunirse con sus respectivas esposas. Al final del acto, el ferrocarril descarrila y desembocan en una fonda donde de-

72 Ibidem, p. 932.

73 Ibidem, p. 932.

74 Ibidem, p. 933.

75 Jacinto Benavente, "Actores españoles y actores franceses", Madrid Cómico, XVIII, 816 (8/X/1898), pp. 13-14; Jacinto Benavente, "El material en la obra dramática”, Heraldo de Madrid, XVIII, 6009 (11/V/1907), p. 4. 
ciden permanecer con unas muchachas de dudosa condición. Carmen, Felisa, doña Jacoba, doña Concha y Gracia acuden a buscarles por temor a que estén heridos y los encuentran, tras un abrir y cerrar de puertas propio de las obras de Feydeau y Labiche, divirtiéndose con las citadas señoritas y sin ninguna intención de volver esa noche a la capital.

En el acto II entran en escena los personajes masculinos de clase mediaalta (los maridos) y de clase baja (el camarero de la fonda, Hilario). Todas las escenas se basan en la comicidad y en los juegos de palabras, cercanos al absurdo; el matrimonio dueño de la hospedería se afana en cobrar más dinero del que les corresponde y los se escudan en poco convincentes excusas tras el encuentro con sus mujeres. En este sentido, se antoja especialmente caricaturesco el dueño de la hospedería, Gaston, francés afincado en España que se asemeja a Adolfo de Rosas de otoño por lo que atañe al uso de la lengua (aunque no encierre un esnobismo ostensible, como éste) y con su repetición constante del adverbio "perfectamente":

Gaston: ¿Han elegido el menú esos señores?

Hilario: Sí, voy.

Gaston: ¿Y qué desean?

Hilario: Por fin han decidido comer de lo que haya.

Gaston: Muy bien pensado. La señorita lo dispondrá todo. ¿Quieren comer en comedor reservado? ¿No es eso? Dos pesetas más por cubierto, perfectamente.

Hilario: No; dicen que si puede ser en el jardín.

Gaston: ¿En el jardín? Cuatro pesetas más por cubierto, perfectamente $^{76}$.

Por otra parte, las señoritas que acompañan a los maridos, tiples de cuplés que tratan de medrar en su profesión, complementan la metateatralidad que iniciaba Jacoba en el acto anterior con nuevas críticas al género chico (en la línea, también, de los artículos benaventinos que giraban en torno a este asunto). Sin embargo, este aparente refinamiento traduce la verdadera vulgaridad de su carácter a través de expresiones francesas demasiado atrevidas:

76 Jacinto Benavente, El tren de los maridos, p. 951. 
PAQuita: Ya veis, en el teatro, ¿qué porvenir podíamos esperar? Cuando no la protegen a una los autores, no hay modo de salir del montón...

PePIta: ¡Y unas exigencias! ¡Quieren que tenga una hasta voz!...

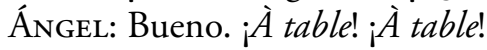

PePita: ¡Allons! ¡Allons!

PaQuita: ¡Va, p’tit cochon! $!^{77}$

El encuentro se produce en la escena 16 del acto II, primero con Dońa Jacoba y en las siguientes con sus esposas. La idea que transmite en la comedia es, en la línea de Rosas de otoño, la aceptación pasiva y resignada del adulterio por parte de la mujer como uno de las reglas del matrimonio: "Vaya; tampoco debéis ser así. Después de todo, hemos llegado a tiempo... ¿y qué marido no descarrila alguna vez? En el viaje matrimonial, nuestro papel... ¡pobrecitas mujeres! Es el de guardaagujas"78.

El pensamiento amoroso que publican las comedias de Benavente desde las primeras sátiras de la aristocracia hacia otras piezas más ligeras evoluciona a la par que el propio género, pues la rebeldía inicial de personajes femeninos como Angelita en Gente conocida, Guadalupe en La farándula o Victoria en La comida de las fieras contrasta notablemente con el pensamiento de Jacoba en El tren de los maridos, de Nené en El hombrecito o de Isabel en Rosas de otoño (esta última con mayor grado de expresión de su pensamiento).

El automóvil, más compleja que la anterior en la tipología de los personajes y en la construcción de la comedia, aunque mantiene la regla del Lara de los dos actos, gira en torno a la rapidez que aporta a la vida de las clases altas la invención de este medio de transporte, cuya novedad genera esnobismo y varios malentendidos.

El ambiente rural en este caso es sustituido por el cosmopolitismo de un casino veraniego "excesivamente modernista"79, acotación inicial que otorga el carácter de cursilería al conjunto de personajes que conforman la comedia. El eje central lo constituye una pareja joven, María Luisa y Federico, que van casarse en los meses próximos y todavía se muestran enamorados.

77 Ibidem, p. 957.

78 Ibidem, p. 980.

79 Jacinto Benavente, El automóvil, en Obras completas, I, p. 1023. 
Alrededor de ellos se sitúan una serie de personajes cómicos entre los que destacan Doña Telesfora (Balbina Valverde), Paquita (Leocadia Alba) y, sobre todo, el Marqués del Suspiro del Toro, que interpretó José Santiago.

Esta comedia guarda estrecha relación con Lo cursi por lo que se refiere al planteamiento amoroso, pues María Luisa defiende las mismas ideas que Agustín y, posteriormente, también las del Gonzalo de Rosas de otoño; los celos de la mujer como forma de poner en ridículo a su marido por falta de elegancia y de distinción. Su frivolidad queda demostrada a través de su visión del matrimonio como ocio y diversión, que complementa bien Federico ${ }^{80}$.

Hilario, padre de María Luisa, se asemeja al carácter de Gonzalo Hinestrosa de La farándula en el discurso político, parodia del orador vacío; pero aporta, en su modo de hablar, un carácter caricaturesco mayor que el del diputado de Moraleda:

Querido Federico: cercano el día en el cual nuestras íntimas y antiguas, y estoy por ańadir, excelentes relaciones, han de estrecharse sólidamente afianzadas por los lazos de la familia, los cuales serán para mí tan gratos como espero, y me atrevería a ańadir lo serán para ti... en cuyo caso será el día más feliz de mi vida... Creo que entre nosotros no debe haber secretos ni tonterías... ¿№ es eso? ¿No es eso? ${ }^{81}$.

Ejemplifica, además, el papel de burgués parvenu que entra en conflicto con la aristocracia, representada por el Marqués.

No obstante, la originalidad mayor de la obra estriba en los personajes antes citados: Doña Telesfora y el Marqués del Suspiro del Toro. La primera, aficionada al juego en el casino, vive con el objetivo de recuperar su fortuna a través de cábalas y cálculos de probabilidades con los números de la ruleta y de otras apuestas. El segundo es presentado en la escena 6 del acto I "elegantemente vestido con un periódico francés en la mano", lo que denota cierto esnobismo que se acentúa con el abuso de los diminutivos y del adjetivo "monina": "Mira; vas a traerme un té hirviendito, hirviendito... y un poco de hielo para enfriarlo, un limón. ¿Entiendes? Unas gotas amargas, un trocito de canela, un huevecito crudo, mostaza inglesa

80 Ibidem, p. 1025.

81 Ibidem, p. 1035. 
y unas cortecitas de pan tostado. ¿Entiendes?”82. El spleen que asoma en su conducta (afirma no haberse casado por "dejadez" ${ }^{83}$, todo le aburre, etc.) le lleva a buscar en el automóvil — del que es dueño- la opción de variar de ambientes y de compañías en pos de la originalidad que no encuentra en la rutina. La vida ociosa lo ha sumido en la ruina, de ahí que Hilario sea ahora su acreedor, con el que negocia con la credencial de su nombre y con la confusión que suscitan en el burgués sus envolventes palabras.

Por ello, El automóvil se configura como un tiovivo de personajes-tipo creados con originalidad respecto al resto de comedias benaventinas y al de los personajes humorísticos del teatro coetáneo, mezcla de la cursilería esnob de las clases altas y de la falta de personalidad, a merced de cualquier inteligencia pícara y astuta.

\section{Dramas de ideas}

La primera obra estrenada por Jacinto Benavente en 1894, El nido ajeno, a pesar de catalogarse como "comedia en tres actos", se acerca más a los dramas de ideas que llevará a las tablas durante el cambio de siglo. Los parlamentos reflexivos, los conflictos pasionales de los tres personajes y los paralelismos con los dramas de Echegaray establecen un nexo de unión con los siguientes, si bien en ellos el simbolismo adquiere una importancia mayor.

Desde 1894 Benavente no había vuelto a acercarse al drama de ideas: apenas un texto breve de carácter dramático - Por la herida, Teatro Novedades de Barcelona, 15 de julio de 1900 - contrarrestaba el dominio de la comedia satírica, que agradaba al público y en la que había sido encasillado. Sus modelos compositivos, basados en la ironía de los diálogos, dificultaban los largos parlamentos reflexivos y la lucha de pasiones.

Probablemente por temor a la recepción entre el público madrileño, Benavente optó por estrenar Sacrificios en el Novedades de Barcelona, más abierto a la diversidad de géneros y estéticas que los teatros de la capital. Su llegada al Español años más tarde amplió sus perspectivas, que trató de iniciar en el teatro de la Comedia con los estrenos de Sacrificios

82 Ibidem, p. 1038.

83 Ibidem, p. 1039. 
- a pesar de que en Barcelona no había logrado una gran acogida — y de Alma triunfante en la temporada siguiente.

Ambos dramas se configuran en torno a un eje central que corresponde con la idea que les da nombre: el valor del sacrificio y la exaltación del alma. Si bien en Alma triunfante es la protagonista femenina quien personifica esta idea, en Sacrificios todos los personajes muestran, desde diferentes ópticas, el verdadero sentido de los sacrificios y del egoísmo humano.

Sacrificios se estrenó en el teatro de la Comedia el 15 de febrero de 1902, en la temporada siguiente a su representación en Barcelona. A través de cuatro personajes, Alma, Ricardo, Esteban y Doll (lo que, en primera instancia, contrasta con el amplio abanico de caracteres de las comedias satíricas) Benavente trató de mostrar las consecuencias de la abnegación humana de dos formas distintas: de manera individualista en los casos de Alma, Ricardo y Esteban y, en contraposición, el altruismo de Doll.

El componente metateatral de este drama es notable y condiciona el desarrollo del conflicto. Alma, huérfana desde muy joven y con una hermana menor a su cargo, dedica su vida a su carrera como cantante lírica, con la que alcanza un gran éxito y paga el colegio para clases altas en el que se educa Doll. En la escena 2 del acto I, Doll critica a sus compañeras de colegio, que censuran la vida de artista de su hermana, mientras que sus madres las llevan allí para que no les molesten durante sus recreos (lo que Benavente había planteado en la carta III de la segunda serie de sus Cartas de mujeres).

Esteban, maestro musical de Alma ha sacrificado su vida para verla brillar y ha condicionado con ello su crecimiento. El paralelismo entre Alma e Imperia — aunque su perfil psicológico sea muy distinto- radica en que, en última instancia, ambas son creaciones de un artista malogrado (Esteban y Leonardo). Sin embargo, la diferencia estriba en que tanto Imperia como otros personajes de La noche del sábado explican el simbolismo del drama mientras que, en el caso de Sacrificios, Esteban niega que este exista subrayando la intención realista del planteamiento de la obra: "En esta lucha, que no es de símbolos, si usted puede personificar el amor, yo no pretendo personificar el arte, pobre y humilde maestro. En el corazón de Alma es donde ha de triunfar usted. No son nuestras ideas, es 
su voluntad la que ha de decidir" ${ }^{84}$.

El drama trasluce, en definitiva, la situación de la mujer en el teatro y su incompatibilidad con la vida matrimonial, que se resume en las palabras de Esteban: “¿La familia! ¡El mayor enemigo del arte!”85.

Ricardo, enamorado de Alma (y correspondido por ella) pretende que deje su vida de artista para casarse con él y ella, que al principio rechaza continuar en los teatros, concluye reconociendo su dependencia de ellos e induce a Ricardo a contraer matrimonio con Doll, su hermana. Éste acepta resignado, pero su idilio con Alma continúa y, cuando Doll lo observa, decide quitarse la vida para que Alma y Ricardo puedan ser felices; lo que acaba frustrándole, ya que ambos sienten entonces que su amor ha sido causa de la muerte de una inocente. El drama fue muy criticado desde el punto de vista moral por el proceder de Alma y, en segundo lugar, por el de Ricardo; el carácter cambiante de aquélla y la maleabilidad de éste no convencieron al público, demasiado conservador para ciertas propuestas ideológicas.

El drama se traba a través de una serie de "sacrificios" que unos personajes exigen a otros: Esteban obliga a Alma a sacrificarse por su carrera artística, ésta induce a Ricardo a sacrificar su amor y aceptar el matrimonio con Doll y la propia Alma sacrifica su carrera y su amor, en principio, por su hermana. Sin embargo, la idea principal de la pieza es que estos sacrificios encierran, en realidad, altas dosis de vanidad y egoísmo; Esteban quiere vivir como el gran maestro de una artista, Alma mantener a Ricardo cerca de ella a la par que poder continuar en los teatros; y Ricardo estar próximo a Alma, para no verse obligado a concluir sus relaciones con la cantante. Doll, contrapunto de todos los demás personajes, encarna el verdadero espíritu de abnegación, sincero y noble: "Para el cariño no existe el sacrificio. Sacrificar la felicidad por quien se quiere, ¿pues qué mayor felicidad?" 86 ; por ello acata las decisiones de Alma sin contrariarlas.

La evolución del personaje de Alma — que pasa del rechazo a la vida de artista en el acto I, donde se muestra luchadora y fuerte, a la frivolidad y a la coquetería en el II y a la amargura y al sentimiento de culpa en el III- genera varias escenas de lucimiento para Rosario Pino, que encon-

84 Jacinto Benavente, Sacrificios, en Obras completas, I, p. 652.

85 Ibidem, p. 650.

86 Ibidem, p. 662. 
tró en Sacrificios el papel más efectista y con más vueltas de tuerca. Las tres escenas (una por acto) entre Alma y Ricardo ofrecen los tres matices distintos de personaje de Alma ${ }^{87}$.

La variabilidad de su carácter es explicada por Esteban en el último acto: "He debido ser más que su maestro de arte. He formado una incomparable artista; pero no es eso todo. ¡Falta la base! Base moral: el arte sin ella es... nada, música, lo único que yo he sabido enseñar" ${ }^{\text {"8 }}$. El tono intenso y declamatorio de sus parlamentos contrasta con la ligereza de otros personajes que Benavente había llevado a las tablas que, los cuales, aunque siempre tenían al menos una escena de lucimiento, no llegaban a la extensión ni al efectismo de este drama (Guadalupe en La farándula, Silvia en La gata de Angora, Rosario en Lo cursi, Josefina en La gobernadora o la Marquesa Rosalinda en Amor de amar).

Sacrificios es, pues, un drama de ideas que, por una parte, se acerca al simbolismo de algunos de sus personajes (en especial, a través de la figura de Doll) y, por otra, posee cierto vuelo melodramático en el tono declamatorio y en los parlamentos. La obra trazará el camino hacia La noche del sábado, donde los desarrollará con formas más complejas y con una gran variedad de géneros y de modelos compositivos.

Alma triunfante se estrenó el 2 de diciembre de 1902 en el teatro de la Comedia y fue el último drama benaventino protagonizado por Rosario Pino en esta sala. El primer espacio en el que se desarrolla la obra —un sanatorio- contrasta con los gabinetes elegantes o los salones de las fincas provincianas de obras anteriores, sedes de frivolidad y ligereza. Por ello las consideraciones irónicas acerca del amor o del adulterio que dominaban la producción benaventina se tornan en este drama en reflexiones severas que oponen religión, ciencia y derechos de los contrayentes.

Andrés, casado con Isabel, que ha perdido la razón tras la muerte accidental de su hija, ha rehecho su vida y formado una nueva familia. Cuando Isabel recupera la razón, Andrés se debate entre su mujer y su hija y, finalmente, es la propia Isabel quien asume la situación y determina el desenlace como alma triunfante sobre el dolor.

En el primer acto, el protagonista debate con el doctor del sanatorio acerca de la posible nulidad del sacramento matrimonial en casos de lo-

87 Ibidem, pp. 657, 669-670 y 678 respectivamente.

88 Ibidem, p. 673. 
cura, que el doctor apoya y la moral cristiana de Andrés desdeña: "La muerte sólo destruye el sacramento; las leyes humanas nada pueden" 89 . El diálogo se desarrolla a través de reflexiones extensas sobre la evolución de la locura en los pacientes desde el punto de vista científico (factores genéticos, de adaptación al medio, choques emocionales, etc.). El tópico del menosprecio de corte y alabanza de aldea que, como método para sanar a los enfermos formaba parte de la mentalidad decimonónica, contrasta con la visión del doctor, que defiende la agitación del medio urbano como acto de valentía y de enfrentamiento a la tristeza o la neurastenia (acto I, escena 1).

El epicentro del acto lo conforman las conversaciones entre Andrés y el Padre Víctor acerca de la resignación cristiana y de la actitud que aquél debe adoptar ante la curación de su esposa (tras su enfermedad, Andrés tuvo una hija con otra mujer y el Padre Víctor le aconseja que la abandone para volver al seno del sacramento). La duda de Andrés, que se debate entre el carińo de su hija y el amor de su mujer es considerada por el Padre Víctor como pecaminosa, pues debe aceptar la justicia divina y olvidar una parte de su vida que un punto más que turbia ${ }^{90}$.

El tono doctrinal y moralista del Padre Víctor resulta novedoso en el conjunto de la producción benaventina, donde la cuestión de la religión o bien aparecía con breves pinceladas anticlericalistas o bien permanecía ausente. Sus personajes, además, nunca adoptaban la actitud sermoneadora de esta pieza sino que, los que criticaban los actos de los demás, ora lo hacían desde la perspectiva del raisonneur irónico, ora a partir de la murmuración frívola.

El final del acto I dista mucho, también, del resto de sus obras. El carácter melodramático y la intensidad de las pasiones contrastan con la tipificación de personajes anteriores y el perfil naturalista de los más graves:

Andrés: ¡Chist! Que no me sienta. ¡Adiós!

Emilia: ¡Espera! ¡Andrés de mi alma! ¿Oyes? "Papá”, "Mamá”... Siempre al despertar...

ANDRÉs: ¡Hija mía! ¡No puedo, no puedo!... ¡Quiero verla! ¡Hija mía!

89 Jacinto Benavente, Alma triunfante, en Obras completas, I, p. 986.

90 Ibidem, p. 994. 
¡No es posible, Dios mío; no es posible! ${ }^{91}$

En el acto II Isabel (Rosario Pino) adquiere una importancia mayor y, a pesar de su brevedad, desarrolla el perfil psicológico del personaje: la esposa de Andrés sospecha de la existencia de otra hija de su marido, que nadie se atreve a revelarle por miedo a que vuelva a sumergirse en la locura. Empero, ella comprende que su curación puede ser un obstáculo entre Andrés y su nueva familia. Por ello finge nuevamente que ha perdido la razón y, en confesión, cierra el acto apuntando al Padre Víctor su verdadero pensamiento, volver al sanatorio para que Andrés encuentre la felicidad perdida. El final abierto del acto, que retoma las disquisiciones morales y religiosas del primero, apunta la idea principal del drama:

¡Mi razón! ¡Está firme, entera! Creen que no... ¡Es tan fácil hacer creer que se está loco!... Usted también me mira con desconfianza; claro, todos los locos dicen lo mismo, que no lo están. No lo estoy, no; al contrario, todo lo que podía enloquecerme ha muerto en mí...: pasiones de odio, de celos, de dolor..., todo lo humano... Sólo queda el alma... ¡Mi alma triunfante! ${ }^{92}$

Si el acto I se configuraba a través de la oposición entre ciencia y religión, el III enfrenta razón y lucidez como estados subjetivos del hombre difíciles de delimitar. El Padre Víctor retoma las palabras finales del acto anterior para explicar el simbolismo del personaje de Isabel: "Cruz de la vida, sí; que es suplicio si al dolor sucumbe el alma; redención si, clavados a nuestra luz, por el dolor resucita triunfante el alma"93.

Almas triunfantes serán varios de los personajes femeninos de Benavente: Angelita (triunfa su individualidad por encima de los intereses sociales), Victoria (ídem que la anterior pero representa el triunfo del amor), Imperia (se imponen su fortaleza y su ambición por encima de otros sentimientos), Isabel (sobresale su resignación y su dignidad como mujer al margen del adulterio), etc. En el comienzo de Sacrificios, Alma es presentada por Ricardo como un "alma fuerte" (acto I, escena 3) pero luego su

91 Ibidem, p. 1000.

92 Ibidem, p. 1010.

93 Ibidem, p. 1019. 
personalidad se debilita y no se alza sobre el dolor o la dificultad como ocurría con las mujeres antedichas.

No obstante, el carácter dramático de esta obra y de las anteriores no radica en el desenlace del conflicto, que posee un tono esperanzador mayor que el de otras comedias, sino en el desarrollo de los actos a través de la exposición de ideas y del debate moral. Su construcción alberga menor complejidad que la de algunas sátiras, pues mantiene la estructura de asunto/acto sin mayores pretensiones que la de llegar al símbolo del alma triunfante.

\section{Teatro escenográfico}

La llegada de Benavente al Español supuso un cambio notable en su dramaturgia y un acercamiento al teatro basado en la plasticidad y en la escenografía. La noche del sábado, obra con la que debutó en esta sala, ofrecía al público una mezcla de estéticas, entre las que destacaba el Modernismo desde distintas perspectivas, que no convenció por resultar demasiado complejo.

Sin embargo, el fracaso de El dragón de fuego fue aún mayor. La trama se organiza en tres actos y un epílogo divididos, a su vez, en nueve cuadros, lo que conllevaba a priori numerosos cambios de decorado. Además, la escenografía de cada uno de ellos no era sencilla: una calle en el Nirván (cuadro 1), gran salón en el Palacio Real (cuadro 2, ambos conforman el acto I); habitación en el Palacio Real (cuadro 3), salón en el palacio del General Duque de Ford (cuadro 4), una cabaña (cuadro 5), la selva de Sindra (cuadro 6, estos forman el acto II); la tienda del rey Dani-Sar (cuadro 7), la terraza del palacio de Sindra (cuadro 8, ambos pertenecen al III) y, finalmente, el salón de un hotel en la capital de Silandia (epílogo). De todos ellos sólo se conserva documentación visual del cuadro 8 (acto III) y de los actores que la representaron ${ }^{94}$.

El telón tuvo que cerrarse ocho veces para poder llevar a término todos los cambios y los intermedios fueron, además, muy extensos porque el montaje ofrecía complicaciones. La obra trataba de abarcar demasiado

94 Se puede acceder a su consulta en la base de datos en línea del Centro de Documentación Teatral (signaturas: FOT 55883-55899). 
y fatigó al púbico, no sólo con las esperas, sino con el excesivo lujo que planteaba, que abrumó la atención de todos. A esto se añadió el carácter multitudinario, mayor si cabe que el de La noche del sábado; treinta personajes figuran en la dramatis personae, además del conjunto de extras: soldados del Nirván, de Silandia, esclavos, gente del pueblo, sacerdotes, músicos, etc.

El contenido tampoco ayudó. La mezcla del colonialismo (todos los cuadros se desarrollan en la colonia y el epílogo se traslada a la metrópoli) con el melodrama, el simbolismo y la sátira aristocrática se reveló como una amalgama sin sentido que indujo a algunos críticos a afirmar que se acercaba a las comedias de magia por lo espectacular visualmente y por la incoherencia interna.

Enrique Gallud dedicó un acertado estudio al análisis de la cuestión colonial y la caracterización del ambiente y del pueblo indio en El dragón de fuego y cita varias fuentes que Benavente pudo conocer antes de componer su obra: el Viaje al pais de los elefantes (1878) de José Muñoz y Gaviria; Las civilizaciones en la India (1901), de Gustave Le Bon; la obra de Kipling; La maison à vapeur, de Jules Verne (1867); y Il misteri della giungla nera y Le dui Tigri, de Emilio Salgari (1857) ${ }^{95}$. De todas ellas Benavente tan sólo conservaba en su biblioteca los textos de Kipling (trece libros) y de asunto indio constan asimismo: National Proverbs India (Anónimo), Indian Poetry and Idylls, de Edwin Arnold; British India, de R. W. Frazer; y The Indian Theatre, de E. P. Horrnitz. Lo que parece seguro es que se había documentado minuciosamente antes de escribir el drama.

La ambientación, como afirma Gallud, responde más bien a una visión simbólica del país colonizado que a una geografía realista. El locativo Nirván procede de "un concepto filosófico hindú en su origen y de aplicación posterior en el budismo que, de manera general, se interpreta como la extinción espiritual del yo individual separado. El nirvâna brahmánico es un perderse en el seno universal del Absoluto, mientras que en el budismo implica la aniquilación en la Nada" ${ }^{" 6}$. El espacio pseudo-simbólico

95 Enrique Gallud Jardiel, “El dragón de fuego. Una comedia india de Benavente”, Indialogs: Spanish Journal of India Studies, 1 (2014), pp. 29-30. Remito a este artículo para el estudio de la temática india y del colonialismo.

96 Ibidem, p. 30. 
benaventino, Suavia, aparece mencionado como parte de la pugna imperialista.

Otros elementos relacionan El dragón de fuego, a pesar de su original exotismo, con el conjunto de la producción benaventina anterior. La hipocresía y la moral de apariencias de las clases altas se subrayan a través de las esposas de los militares, que protagonizan escenas cosmopolitas independientes de la trama principal ${ }^{97}$.

Especialmente significativa es la presencia del bufón Kirki, de perfil shakespeariano, que asiste al príncipe adoptando una postura seria y muy crítica (paralelamente al planteamiento de Harry Lucenti en La noche del sábado ${ }^{98}$. La mezcla tragicómica del bufón captó la atención de Benavente también en sus textos publicados en prensa: la presentación de Pepita Castrojeriz en "Vírgenes locas. Escenas de la vida moderna" y, sobre todo, "Los clowns", publicado en Blanco y Negro el 12 de mayo de 1900. En este artículo reflexiona sobre la inspiración del clown en la obra del dramaturgo isabelino, por medio de los cuales traslucía la mezcla tragicómica de la vida y exteriorizaba sus más profundos pensamientos ${ }^{99}$.

El dragón de fuego se diferencia de todas sus obras anteriores en la impronta de los pensamientos hinduistas y en su configuración a través de extensos parlamentos pronunciados, sobre todo, por Duraní, Dani-Sar y Mamni (el matrimonio Guerrero-Mendoza y Calvo). El ritmo de cada cuadro es notablemente más lento y el asunto amoroso queda supeditado al belicismo de la liberación y a la pugna de intereses personales (traidores que apoyan a los dos bandos, tratamiento misógino de las doncellas, etc.). La evolución de la trama hasta el delirio de Dani-Sar por la traición de Nagpur y de los imperialistas se torna compleja y aglutina planteamientos melodramáticos (como el triángulo amoroso que se asienta entre Duraní, Sita y Dani-Sar), la tiranía de la mujer a través de Mamni, imperialismo y liberación, reflexiones religiosas, comunión entre el cosmos y el individuo, etc.; todo ello enmarcado por un intenso colorismo en el vestuario y en la ambientación.

La princesa Bebé fue escrita para la temporada de 1904-1905 pero no se estrenó hasta 1906, aun cuando el público la había podido leer en su

97 Jacinto Benavente, El dragón de fuego, en Obras completas, II, pp. 350-351 y 377.

98 Ibidem, pp. 371-372.

99 Jacinto Benavente, "Los clowns", Blanco y Negro, X, 471 (12/V/1900), p. 20. 
primera edición. Sin embargo, establece una línea de continuidad entre La noche del sábado y, en menor medida, El dragón de fuego. En primer lugar, por ser una de las grandes producciones benaventinas para el Español (hasta el punto de que llevó al déficit de la empresa al final de la campaña) $y$, en segundo, porque retoma personajes, argumentos e ideas presentes en las dos obras anteriores.

A su planteamiento como "escenas de la vida moderna", que la relaciona con Gente conocida y, en cierto modo, con La noche del sábado - mutatis mutandis - se une la división en actos con decorado distinto $y$, en algunos de ellos, similar al de la pieza anterior. Además, Benavente ofreció al espectador un conjunto de personajes cuya adscripción a $L a$ noche del sábado no es directa pero acusa paralelismos notables.

La acción se desarrolla en un salón del palacio de Suavia, reino al que pertenecen los nobles de La noche del sábado y que corresponde, por distintas referencias en ambos textos, con la zona alemana real de Suabia, en la región de Baviera. La obra finalizaba con la decisión de ascenso al trono del Príncipe Miguel e Imperia, que se convertirían en Emperadores de Suavia. En La princesa Bebé, el Emperador se llama, como el Príncipe de La noche del sábado, Miguel Alejandro y de la Emperatriz (que no aparece en la obra, sólo mencionada) no se alude al nombre. Parece que con ello Benavente pretendió dar continuidad generacional a los personajes, de los que se recrea el final de su reinado (habrían transcurrido, aproximadamente, tres décadas desde la acción de La noche del sábado).

Además, una de las ideas fundamentales de La princesa Bebé es la moralidad de apariencias, que no se ciñe únicamente a la clase aristocrática, sino que afecta, y en mayor medida, a los burgueses parvenus o a las clases bajas ascendidas por sus matrimonios con nobles. La princesa Elena (princesa Bebé) abandona su palacio y a su marido para marcharse a otros mundos con el secretario de éste, Alberto Rosmer, deseosa de vivir a través de la verdad y alejarse de los convencionalismos que le han sido impuestos por su nacimiento. Sin embargo, tiempo después observa que estos convencionalismos son todavía más exagerados por los aristócratas advenedizos que quieren olvidar su pasado, por lo que decide unirse a las clases bajas y dejar salir su "alma bruja” junto a la del Príncipe Esteban.

La noche del sábado presenta una idea similar a través del personaje de Imperia, que representa precisamente el deseo de ascenso social del 
pueblo por medio de la voluntad individual de un ser fuerte que persigue su sueño por encima de todo. Quizá por ello Benavente guarde el anonimato de la Emperatriz, pues la propia evolución del personaje le hubiera llevado a formar parte de un núcleo social donde se perdería su carácter individual, difuminado entre el resto.

El Emperador Miguel de La princesa Bebé origina la acción de la obra, pues rechaza el divorcio de la Princesa Elena y el matrimonio del Príncipe Esteban, primo de ésta, con una cantante de opereta. Esta intransigencia contrasta con el origen de su propio matrimonio (si, como parece, se trata del mismo personaje que el de La noche del sábado), pues Imperia había sido modelo, bailarina y amante antes de convertirse en Emperatriz. De hecho, la Princesa Margarita se burla en el acto I del comportamiento de los príncipes y emperadores de Suavia del siglo XX, que ya no se ven como espejo de virtudes, como sucedía con los anteriores. En La noche del sábado, además, los linajudos de Suavia manifiestan el mismo comportamiento hipócrita, los mismos vicios (al juego, principalmente) y las mismas relaciones con miembros de la perduta gente que en La princesa Bebé.

Otro dato acerca los personajes de ambas obras: en La noche del sábado el Emperador, de avanzada edad, decide abdicar del trono tras el fallecimiento del bebé heredero, y siendo entonces sucedido por el Príncipe Miguel, hermano de la Emperatriz. En La princesa Bebé el Príncipe Esteban afirma no haber conocido a su padre, por lo que bien puede tratarse de un hijo posterior al fallecimiento de aquél.

Al margen de los parentescos y de los asuntos, los paralelismos se hallan principalmente en la escenografía. El acto II de La princesa Bebé -el de mayor importancia en el conjunto de la obra- tiene lugar "en una estación de invierno, entre Italia y Francia. Gran salón en el Casino”. Esta estación de invierno es exactamente la misma que la del primer cuadro de La noche del sábado. Las fotografías de La princesa Bebé que hoy se conservan en las revistas El Arte del Teatro y Blanco y Negro sólo testimonian la escenografía de los actos III y IV ${ }^{100}$, por lo que no es posible comprobar si el Español se valió del mismo decorado para montar ambas piezas, lo que

100 Jacinto Benavente, "La princesa Bebe", El Arte del Teatro, I, 3 (V/1906), pp. 5-6 y "Estreno de La princesa Bebe", Blanco y Negro, 779 (7/IV/1906), p. 16. Accesibles para su consulta en las páginas web de la Hemeroteca Digital de la Biblioteca Nacional de España y de la Hemeroteca de $A B C$. 
resultaría de sumo interés para probar su filiación.

Además, tanto el acto II como el cuadro I plantean la cuestión de la hipocresía de la aristocracia de manera similar; el esnobismo de los personajes y el rechazo aparente a los vicios descansa en los dos textos sobre la sátira mordaz, con el matiz de que en La princesa Bebé se trata de aristócratas parvenus y en La noche del sábado de nobles de sangre. Todos ellos buscan en la estación de invierno alejarse de sus vidas. "La noche del sábado" representa la búsqueda de la felicidad a través de recreos alejados de los convencionalismos, y por eso se explica con la "salida de las almas brujas" hacia la verdad de sus sentimientos y de sus depravaciones.

Por otra parte, el acto III de La princesa Bebé acontece en una sala en la villa del conde de Tournerelles, y el cuadro IV de La noche del sábado un gabinete en la villa de Imperia, pero el decorado fue distinto; más complejo en la primera obra, donde se diferenciaban dos planos frente al único de la segunda.

El paralelismo entre ambas piezas no sólo se produce en el paso del acto II al III de La princesa Bebé y del cuadro II al IV de La noche del sábado, sino también en el planteamiento general del acto IV y cuadro III, respectivamente, que retrata una parte del hampa de la taberna de Cecco, en la novela escénica, y un restaurante al aire libre en las escenas de la vida moderna. En ambos actos, un personaje femenino, ausente en el resto de la obra, adquiere especial relevancia: Maestá, en La noche del sábado y La Degollada, en La princesa Bebé. A ambos personajes los rodea un conjunto de miembros de las clases bajas que configuran el ambiente de la perduta gente (valentones, alcohólicos, ladrones e incluso asesinos), acompañados de la música de vals en La princesa Bebé y de tarantelas en La noche del sábado.

Por todo ello, La princesa Bebé se configura como una continuación temática de La noche del sábado y, al mismo tiempo, de las formas dramáticas planteadas en Gente conocida a través del apelativo "escenas de la vida moderna”.

\section{OBRAS BREVES}

A las diecinueve obras mayores a un acto que Benavente escribió y re- 
presentó entre 1894 y 1905 las escoltan doce piezas breves que abarcan diversos géneros: bocetos de comedias, comedias, dramas, un sainete, un chascarrillo, un apropósito y un monólogo.

Peral Vega estudió el teatro breve benaventino en términos generales y remitió al ensayo Teatro del pueblo de 1909, donde el dramaturgo madrileño defendió este tipo de obras por cuatro razones: la necesidad de renovación del teatro decimonónico y de los géneros grandes, que perdían éxito frente al género chico y a la acogida del cinematógrafo; la "bofetada de modestia" a los autores afamados, que debían reducir sus intrincados argumentos a un acto; la vuelta al teatro del Siglo de Oro y las posibilidades de experimentación que ofrecía (menor inversión para los empresarios y mayor libertad para los creadores) ${ }^{101}$. Asimismo, apuntó las líneas generales de caracterización de sus obras breves (sátira y crítica social, metateatro, feminismo, ambigüedad sexual, absurdo, teatro musical, etc.).

A pesar de los problemas de clasificación genérica que ofrece el teatro breve, Benavente delimitó con cierta claridad tres grupos: bocetos de comedias, comedias y dramas. La diferencia entre estos grupos es notoria tanto por el tipo de escenas y diálogos como por el tratamiento de los asuntos; no así la que media entre los dos primeros, que no presentan rasgos dispares que los determinen genéricamente. Tanto los bocetos de comedias como las comedias proponen tramas breves cerradas que podrían haberse planteado como obras largas sin que exista una estructura más clara en las comedias que en los bocetos.

El primero aglutina dos obras de temática muy distinta: El marido de la Téllez — Teatro Lara, 13 de febrero de 1897-y Sin querer — Teatro de la Comedia, 3 de marzo de 1901—. El marido de la Téllez ha sido analizada en varias ocasiones, pues el componente metateatral trasluce las opiniones de Benavente acerca de sus coetáneos y de la organización teatral del momento, lo que captó el interés de la crítica ${ }^{102}$. Sin querer esboza la historia de Luisa y Pepe (éste representado por el propio Benavente a beneficio de Rosario Pino), dos primos a los que sus familias habían decidido unir en matrimonio sin su aprobación. En un primer momento se opusie-

101 Emilio Peral Vega, "El teatro breve de Jacinto Benavente", Cuadernos para la Investigación de la Literatura Hispánica, 29 (2004), pp. 17-19.

102 Enrique Gallud Jardiel analiza la obra en "Jacinto Benavente y su visión satírica del teatro por dentro", Anagnórisis: Revista de Investigación Teatral, 3 (2011), pp. 76-92. 
ron pero, tras conversar y conocerse, se enamoraron y decidieron casarse por su propia voluntad, aun cuando los padres no habían llegado a un acuerdo sobre la dote. La parodia de los matrimonios concertados, que ya apuntó Peral, se lleva a cabo desde una perspectiva cómica y mordaz, similar a la de las primeras sátiras. El chiste cobra en ella especial importancia, sobre todo en la figura de Pepe:

LuIsa: ¡Qué bonito! Querer a un hombre, casarse con él y, al poco tiempo, que aquel hombre sea otro hombre...

Pepe: Un marido de gran espectáculo, con mutaciones ${ }^{103}$.

Desde otro punto de vista, la frivolidad y la hipocresía en el amor está presente en Despedida cruel, estrenada en el marco del Teatro Artístico en el Lara el 7 de diciembre de 1899. Como afirma Peral,

Respecto de las relaciones amorosas, Benavente está muy lejos de asumir las convenciones al uso en el teatro coetáneo. Más bien al contrario, se propone destapar, a través de una mirada irónica, escéptica y, por qué no decirlo, a ratos desencantada, la hipocresía que se esconde tras las formas más arquetípicas del amor ${ }^{104}$.

El argumento de la obra es el siguiente: Casilda y Pepe se ven obligados a finalizar sus relaciones extramatrimoniales por motivos económicos y familiares; al principio, la tristeza parece anidar en los protagonistas, pero, conforme avanza la comedia, torna en la más absoluta indiferencia y se demuestra que sus amoríos han sido para ellos sólo un divertimento. Resulta interesante la oposición entre el amor verdadero y el amor razonable enunciada por Casilda, que concuerdan con el pensamiento benaventino expuesto en otras obras ${ }^{105}$. La hipocresía burguesa está también presente en la caracterización del tío de Pepe ${ }^{106}$, e incluso se apunta la crítica política: "En cuanto se anda mal de dinero, ya se sabe, a regenerarse. Ahora todos nos regeneramos" 107 .

103 Jacinto Benavente, Sin querer, en Obras completas, I, p. 638.

104 Emilio Peral Vega, op. cit., p. 26.

105 Jacinto Benavente, Despedida cruel, en Obras completas, I, p. 426.

106 Ibidem, p. 428.

107 Ibidem, pp. 427-428. 
En Operación quirúrgica - Teatro Lara, 4 de mayo de 1899- Benavente aborda, desde una perspectiva más dramática que en las comedias anteriores, el papel de la mujer ante el adulterio. Clara se separó de su esposo por una infidelidad y, tras un periodo de tiempo, éste le escribe pidiéndole que regrese a su lado. Su cuńado Hipólito, quien lleva el peso de la comedia, le aconseja que acceda a su ruego obligándole, así, a perdonar el engaño.

El adulterio se justifica en la obra por ser costumbre habitual en la sociedad: "La falta de Luis fue la más natural en su caso. De las que todos los maridos cometen a escondidas, y todas las mujeres perdonan a sabiendas" 108 , lo que se contrapone al pensamiento de Clara, que piensa que si ella se sacrifica, por su deber su marido y la sociedad nada podrán exigirle (escena 1). La obra concluye con un final triste y de resignación en el seno del matrimonio, próximo, pues, al de Por la herida y Rosas de otoño ${ }^{109}$.

Por qué se ama - Teatro Español, 26 de octubre de 1903- desarrolla la idea del amor como fruto del agradecimiento en vez de como sentimiento espontáneo. De extensión similar a las comedias anteriores, posee un carácter marcadamente reflexivo y de mayor lucimiento para los actores (no en vano fue la primera pieza breve que Benavente estrenó en el Español).

El argumento gira en torno a cuatro personajes, Emilia, María Luisa, Andrés e Isidoro, relacionados entre sí por sus sentimientos. Andrés, hombre distinguido y honrado, ama a Emilia, y ésta cree que debe corresponderle como reconocimiento a sus cuidados y consideraciones. Sin embargo, se enamora de Isidoro, joven mujeriego y vividor al que la alta sociedad aparta y niega su regeneración. María Luisa, por su parte, ama a Andrés, que se muestra indiferente, e Isidoro a María Luisa, que lo detesta. Finalmente, prevalece el amor sobre la gratitud y Andrés se aleja de Emilia cuando descubre que la dama quiere a Federico.

En esta comedia figura un personaje, interpretado por María Cancio, que entraña cierto interés por su perfil simbolista: Doña Jacoba. Amante de los animales, es capaz de intuir los sentimientos humanos y de com-

108 Jacinto Benavente, Operación quirúrgica, en Obras completas, I, p. 411.

109 Ibidem, p. 421. 
prender la complejidad del alma ${ }^{110}$. Su papel responde, más que a criterios dramatúrgicos, a una decisión empresarial; Benavente buscó un papel de lucimiento para la Cancio, tal como hiciera en otras obras, verbigracia La noche del sábado.

Por la herida y La casa de la dicha - Teatro de las Artes de Barcelona, 9 de diciembre de 1903 - , las dos piezas breves benaventinas catalogadas bajo el título de "dramas", fueron estrenadas en Barcelona (la primera en el Novedades y la segunda en el teatro de las Artes). Por la herida es el melodrama más cercano al teatro de Echegaray de toda la producción breve estrenada por don Jacinto en sus diez primeros años de escritura. La obra gira en torno a un duelo anunciado entre Federico, marido de Felisa y Carlos, su amante. En un principio Felisa piensa que es por su culpa, pero, en realidad, la razón es una amante común a ambos. La Marquesa de San Severino y Mercedes personifican a la aristocracia chismosa de todas las sátiras anteriores, que acuden a casa de Felisa con la excusa de advertirle, mas, en realidad, quieren vivir el conflicto en primera línea.

El choque entre la alta burguesía y la aristocracia está presente a través de la Marquesa y Carlos. Aquélla afirma que éste, que no es aristócrata, ha accedido al duelo para demostrar que la nobleza tiene menos valor que la burguesía y compromete a Felisa más por vanidad que por cariño (escena 3). El final, marcadamente efectista, se desarrolla con un elemento central: unas cartas de Carlos que Felisa muestra a Federico para herir su orgullo. Éste se indigna y le pide que se marche de casa, pero después rectifica por miedo a un escándalo (una idea similar contrastaba ya en $E l$ hombrecito, pero con un enfoque contrario, el de los amantes). El adulterio aceptado con naturalidad, que es constante en los textos finiseculares, caracteriza a Federico como marido muy distinguido porque, cuando se acerca a otra mujer, no pone en ridículo a la suya sino que le organiza un viaje a París ${ }^{111}$.

Finalmente, La casa de la dicha, pieza intrascendente, presenta un conflicto familiar dramático dotado de cierta ironía. Una familia conocida en la alta burguesía por la felicidad que mostraba al exterior es finalmente separada por el encarcelamiento del marido, falsificador de billetes. El drama surge de la situación de la hija pequeńa, que pierde a sus padres cuan-

110 Jacinto Benavente, Por qué se ama, en Obras completas, II, p. 87.

111 Jacinto Benavente, Por la herida, en Obras completas, I, p. 534. 
do los detienen y debe quedarse con una amiga de sus padres. Benavente se centra en la infancia como víctima de los conflictos paternos, que en el teatro francés de la época fue un asunto recurrente.

La parodia política predomina en Modas, pues el resto de sus piezas breves se ciñen al argumento amoroso o metateatral. Este sainete es el texto en un acto de mayor complejidad en la primera década benaventina y el que presenta un abanico mayor de personajes. Todos ellos frecuentan el taller de madame Tutú, modista afamada de las clases altas que finge ser francesa, pero no pasa de ser, en realidad, una antigua actriz de variedades. Esta obra aglutina la mayor parte de los asuntos que el dramaturgo madrileño trató en sus comedias: sátira aristocrática, parodia de la vida y la política de provincias, metateatro, amor y matrimonio y esnobismo francés.

Las dos primeras escenas critican el carácter caprichoso de las clases altas, que todo lo desean, exigiendo la máxima atención en aras de su condición. En la escena siguiente, una primera actriz trasluce los intereses del público en el teatro: debe gastar todo su dinero en toilettes porque es lo que verdaderamente valoran los espectadores (Benavente ya lo había criticado en un artículo) ${ }^{112}$. Por otro lado, censura la tiranía de las actrices que intervienen en las obras con criterios extrateatrales y eliminan del texto todo cuanto no las favorece.

La escena 4 se relaciona directamente con La gobernadora y con $E l$ primo Román: Amalia y Concha, madre e hija de Moraleda y familia del Presidente de la Diputación, acuden al taller fingiendo cierta distinción y con el objetivo de ver cuáles son las modas y no comprar absolutamente nada. Un diputado que necesita granjearse su apoyo se ve obligado entonces a acompañarles y a sufrir el ridículo consecuente, fruto de la actitud de Amalia y del empeño de su hija en hablarle en francés a Madame Tutú.

A continuación, entra un Celoso que parodia las infidelidades que cometen las mujeres con la excusa de que van a la modista (subtema que Benavente había planteado ya en "Historia de un día en tres esquelas"113). En este caso se trata de una viuda trapisondista que vive de los regalos de sus amantes (escenas 5,10 y 11 ).

112 Jacinto Benavente, "De sobremesa”, El Imparcial, XLI, 14609 (18/XI/1907), p. 3.

113 Jacinto Benavente, "Historia de un día en tres esquelas", El Bambú, I, 5 (10/ XII/1897), p. 6. 
La profusión de personajes de este sainete convierte a la pieza en un acto en el esbozo más claro de la escena suelta aplicada a un texto representable, en sus límites más reducidos.

De carácter metateatral, paralelo a El marido de la Téllez es Teatro feminista, apropósito estrenado en el teatro de la Comedia con motivo del día de los Inocentes de 1898, con música de Pablo Barbero ${ }^{114}$. En él se ponen en solfa las bases del feminismo de pose pero no de fondo: las condiciones que impone la Directora al principio de la obra son muy estrictas (no pueden entrar los maridos, si alguna señora quiere ir acompañada de un familiar masculino debe dejarlo en el guardarropa — donde se le dará un número para evitar pérdidas o equivocaciones_- van a luchar contra las injusticias y los atropellos que sufren las actrices). Sin embargo, las obras que representan pertenecen a autores masculinos consagrados (Echegaray, Guimerá, Ramos Carrión), renuncian a apoyar el divorcio, porque antes prefieren reivindicar el matrimonio (escena 1), y terminan sucumbiendo a la creación de un teatro chic y smart donde las mujeres se vistan de forma elegante para agradar a los hombres (escena 7).

No fumadores, definido como "chascarrillo en acción", fue estrenado el 3 de marzo de 1904 en el Lara a beneficio de Leocadia Alba. En la línea de las comedias ofrecidas por Benavente en esta sala, sin ideas complejas y con personajes tipo (en este caso incluso sin nombre - Una Señora, Una Señorita, Un Caballero y Un Revisor-) centra su desarrollo en la propia comicidad de la acción, que tiene lugar en un vagón de tren. Una señora y su hija deciden cambiarse de coche, indignadas ante la frivolidad de dos mujeres que leían un libro demasiado atrevido y mantenían conversaciones indecorosas para los oídos de una muchacha. En el vagón coinciden con un caballero al que la señora cuenta sus problemas familiares, la situación de su hija, la visita a la que se dirigen, etc. El caballero, harto de escucharlas, baja del vagón en la primera parada y ellas, que piensan que no va a regresar y que ha perdido el tren, arrojan su equipaje por la ventana para que lo encuentre cuando se dé cuenta de que han partido sin él. Cuando regresa el caballero y advierte lo ocurrido, entabla una discusión con la seńora, que no llegará a rematarse y termina abierta, como la pri-

114 Para el teatro musical benaventino, véase María Pilar Espín Templado, "Jacinto Benavente, autor de género chico", en La zarzuela de cerca, ed. Andrés Amorós, Madrid, Espasa-Calpe, 1987, pp. 163-205. 
mera parte del Quijote, con las espadas en alto.

La obra se cifra únicamente en el lucimiento de Leocadia Alba, quien lleva el peso del diálogo; la señorita y el caballero tan sólo responden o le dan las entradas. Cada una de las intervenciones de la protagonista se convierte en monólogos breves en los que Benavente hila, sin demasiada coherencia, distintos pensamientos (la costumbre de fumar, la falta de moralidad de los jóvenes, la mala relación con su cuñada, etc.).

Así pues, el teatro breve del madrileño evoluciona de forma paralela al conjunto de sus obras largas representadas. Comienza con comedias o bocetos de comedias basados en la sátira y la crítica social (El marido de la Téllez, Despedida cruel, Teatro feminista o Modas) y se dulcifica después hacia obras de asunto amoroso ligero (Sin querer, Por qué se ama). El acercamiento al drama se produce, en primer lugar, con el desenlace de Operación quirúrgica, para llegar más tarde a los estrenos en Barcelona, muy distintos entre sí: Por la herida y La casa de la dicha. Además, los chascarrillos del Lara, la mayoría a beneficio, ofrecen la faceta del Benavente más cómico y fueron los más celebrados por el público.

\section{Breves notas Sobre algunas analogías ENTRE las obras de BenaVENTE}

El universo benaventino se configura también a través de la repetición o alusión a personajes recurrentes en sus comedias (los dramas no presentan analogías) o en las escenas sueltas publicadas en la prensa. Todas sus criaturas pertenecen a las clases altas, a la burguesía adinerada o a la aristocracia y crean, así, el "Todo Madrid” planteado desde Gente conocida.

El personaje con mayor frecuencia de aparición en su primer teatro es Manolo Castrojeriz. Además de las varias ocasiones en las que interviene como personaje en Rosas de otoño es mencionado en Lo cursi, donde contrasta con el carácter que se le impone en los demás textos. En esta comedia es el pretendiente de Lola y está bien considerado por la sociedad, frente a sus otras caracterizaciones como soltero vividor. Desempeña la profesión de ingeniero de buena familia y la diferencia entre este perfil y los anteriores apunta la posibilidad de que Benavente utilizase el apellido Castrojeriz para referirse genéricamente a un miembro cualquiera de las clases altas con papel secundario, representante de un grupo y no de un 
individuo particular.

En este sentido, el apellido Robledal aparece también en diversos textos (La farándula, Gente conocida o Noches de verano ${ }^{115}$ ) cambiando, a veces, el título que lo acompaña (condesa, marquesa, etc.), por lo que adquiere el mismo valor genérico que el anterior: un miembro más del Todo Madrid. Lo mismo sucede con Fermín Antón, que es personaje de La comida de las fieras y "Escenas íntimas"116 y aparece aludido en "En pública subasta"117 y Modas. No obstante, el propio Benavente explicó que el apellido Antón (que no era ni siquiera apellido sino nombre) designaba a una persona sin identidad propia ${ }^{118}$.

La Marquesa de San Severino, que había desfilado por "Con quién y sin quién"119, La comida de las fieras y Gente conocida, es uno de los personajes principales de Por la herida y mantiene el carácter de aristócrata murmuradora de dichos textos. Resulta significativo que en esta obra se la mencione por su nombre de pila, Pilar, que hasta el momento había permanecido oculto tras su título nobiliario.

Además, en algunas comedias Benavente aludió indirectamente a otras obras para establecer filiaciones entre ellas a través de los distintos lugares donde se desarrollan. Buena parte de los actos de sus sátiras de las clases altas tienen lugar en bailes en los que se recurre a la analogía de personajes, siempre alrededor del universo de Moraleda, espacio de las comedias de provincias. En Modas, sainete urbano, aparecen dos personajes procedentes de Moraleda, y en El hombrecito también hace un breve guiño al taller de Madame Tutú ${ }^{120}$.

A pesar de que las analogías benaventinas no son complejas ni ahondan en distintos rasgos de la conducta de sus personajes, como sí ocurre en

115 Jacinto Benavente, Noches de verano, Madrid, E. Rojas, 1900. Edición en la que se recogen, entre otros, los textos publicados con título homónimo previamente en $\mathrm{El}$ Imparcial, XXXI, 10847 (12/VII/1897), p. 3 y XXXI, 10903 (6/IX/1897), p. 3.

116 Jacinto Benavente, "Escenas íntimas”, El Imparcial, XXXI, 10757 (12/IV/1897), p. 3.

117 Micifut [seudónimo de Jacinto Benavente], "En pública subasta”, El Globo, XXII, 7495 (25/V/1896), p. 2.

118 Ibidem, p. 2.

119 Jacinto Benavente, “Con quién y sin quién”, La Época, XLVIII, 16725, (25/ XII/1896), suplemento ilustrado, p. 1.

120 Jacinto Benavente, El hombrecito, p. 45. 
las novelas galdosianas, sirven para configurar un universo de clases altas donde la propia pérdida de la personalidad individual, que se difumina con el medio, es muy significativa. El Todo Madrid benaventino rodea a algunas almas fuertes que tratan de alzarse contra él y a otras que terminan sucumbiendo ante los convencionalismos sociales.

Así pues, en primera década como dramaturgo Benavente propuso diferentes asuntos y planteamientos teatrales que experimentaron una evolución relevante desde su irrupción en la escena con El nido ajeno hasta el triunfo de Rosas de otoño. Su fama se consolidó con la sátira de clases altas, que inició en Gente conocida y continuó hasta el cambio de siglo, tanto cosmopolita (Gente conocida, La comida de las fieras, La gata de Angora) como provinciana (La farándula o La gobernadora). Los conflictos entre la aristocracia decadente y el ascenso de la burguesía parvenue de negocios originaron una red de intereses que afectaban, sobre todo, al matrimonio, en el que unos buscaban mantener sus fortunas y otros alcanzar un título nobiliario. Los personajes encarnan vicios sociales y su complejidad psicológica es mínima, lo que va cambiando conforme evolucionan las comedias. Así, en La gata de Angora se iguala la sátira con las pasiones de los protagonistas y el asunto amoroso adquiere un fuste mayor que en sus obras anteriores. Este planteamiento se consolida en Lo cursi, que ofrece una visión práctica de la ambigüedad del concepto en el cambio de siglo, que afectaba a todos los comportamientos esnobs de las clases adineradas.

Paralelamente, Benavente dedicó su atención a la vida de provincias y a la política que la condicionaba. En primer lugar, plasmó en La farándula la hipocresía y la vacuidad del discurso político de los diputados que trataban de buscar apoyos de provincia en provincia, como si de una compañía cómica itinerante se tratase. Ideas similares presentó en El primo Román, pero desde una perspectiva individualizadora y con el asunto amoroso como argumento central. La gobernadora, por otra parte, censura el caciquismo y, al mismo tiempo, propone un personaje femenino fuerte en el matrimonio, pero vacilante en el trance del adulterio. Por último, Al natural deja paso a la comedia amorosa frente a la sátira política.

La mayor parte de sus primeras comedias largas fueron estrenadas por Benavente en el teatro de la Comedia y en el Lara. Las primeras, de variedad temática y formal mayor, aglutinan desde sátiras hasta dramas, mientras que las segundas presentan un patrón compositivo similar. Es- 
tructuradas en dos actos, dejan paso a la comicidad y al humorismo sobre cualquier otro elemento, con profusión de personajes tipo y caricaturescos y ausencia total de reflexiones ideológicas o moralistas.

En los años que siguieron al cambio de siglo, don Jacinto se acercó al drama de ideas con dos textos: Sacrificios y Alma triunfante, que explotaban algunos preceptos que había sugerido ya en El nido ajeno. Ambas piezas se estrenaron primero en Barcelona y después fueron llevadas a la capital y, con ellas, desaparecía completamente la ironía y se dejaba paso a la reflexión introspectiva y, sobre todo, a las discusiones morales.

En 1903 Benavente estrenó por primera vez en el teatro Español, y la obra que llevó a las tablas — La noche del sábado - era notablemente más compleja que las anteriores. La variedad de géneros (sátira, melodrama, drama de ideas) que aglutinaba, el simbolismo de los personajes y el Modernismo del prólogo abrieron un camino nuevo de propuestas benaventinas, que tendría como base la plasticidad de la escenografía. La obra que le sucedió, El dragón de fuego, fue la más original de toda su producción tanto por el exotismo como por la complejidad escénica y, por ello, no fue del agrado de la crítica ni del respetable. Algo similar sucedió con $L a$ princesa Bebé, en la que se acercaba nuevamente a la sátira de clases altas, manteniendo, eso sí, la diversidad visual de la obra.

Por último, compuso, a la par que las obras largas, doce piezas breves en un acto de diversa filiación genérica: bocetos de comedias, comedias, dramas, chascarrillos, etc., que estrenó en sus teatros habituales (Comedia y Lara, principalmente y, después, Español y otras salas). En algunas de ellas esbozaba o expandía asuntos previamente transitados (amorosos o sociales), y en otras dejaba libre paso al humorismo y a la búsqueda de la risa del espectador. Al mismo tiempo, garabateaba dramas de temática menos trascendente que no sedujeron tanto a la platea como sus piezas cómicas. 